\title{
Los orígenes académicos del romanticismo histórico español: Malestar y crisis en torno a 1792
}

\author{
José Enrique Garcia Melero
}

Entre 1786, año de la creación de la Junta de la Comisión de Arquitectura de la Real Academia de Bellas Artes de San Fernando, y 1808, fecha del inicio de la Guerra de la Independencia, este organismo intentó reformar sus planes de estudio, en general, y de la arquitectura, en particular, para adecuarlos a los cambios experimentados por la teoria y la práctica del arte del momento. Un espiritu novedoso de renovación -parecía haberse ya impuesto el nuevo clasicismo en el Reino, pero aún soplaban los últimos vientos barrocos-se percibe en este organismo, que durante estos años, especialmente en el entorno de 1792, pasó por uno de sus periodos más críticos debido a las intensas polémicas, que se produjeron en su seno y que inmiscuirian de alguna forma a sus diversos estamentos.

Los viceprotectores, primero Bernardo de Iriarte y después el Marqués de la Espeja, convocaron una serie de juntas extraordinarias durante este periodo de tránsito entre los siglos XVIII y xIX, para que en ellas se estudiaran detenidamente los medios necesarios para mejorar el nivel de la enseñanza de la arquitectura en la Academia e imponer definitivamente ese nuevo clasicismo. Pero los resultados obtenidos no parecen obedecer a los deseos de cambios, que ambos tenian. Cierta inercia y en ocasiones la misma acritud de las polémicas entabladas restaron muchas veces efectividad a estas reuniones y no se materializaron en medidas concretas, sino más bien en una inquietud generalizada, que llegaria a cuestionar el papel mismo desempeñado por este centro artístico.

El plurifuncionalismo ambiguo de ese instituto, criticado por el propio Juan de Villanueva (fig. 1), debió restar efectividad a tales reformas, al hallarse a medio camino entre una Academia y una Escuela de las Bellas 


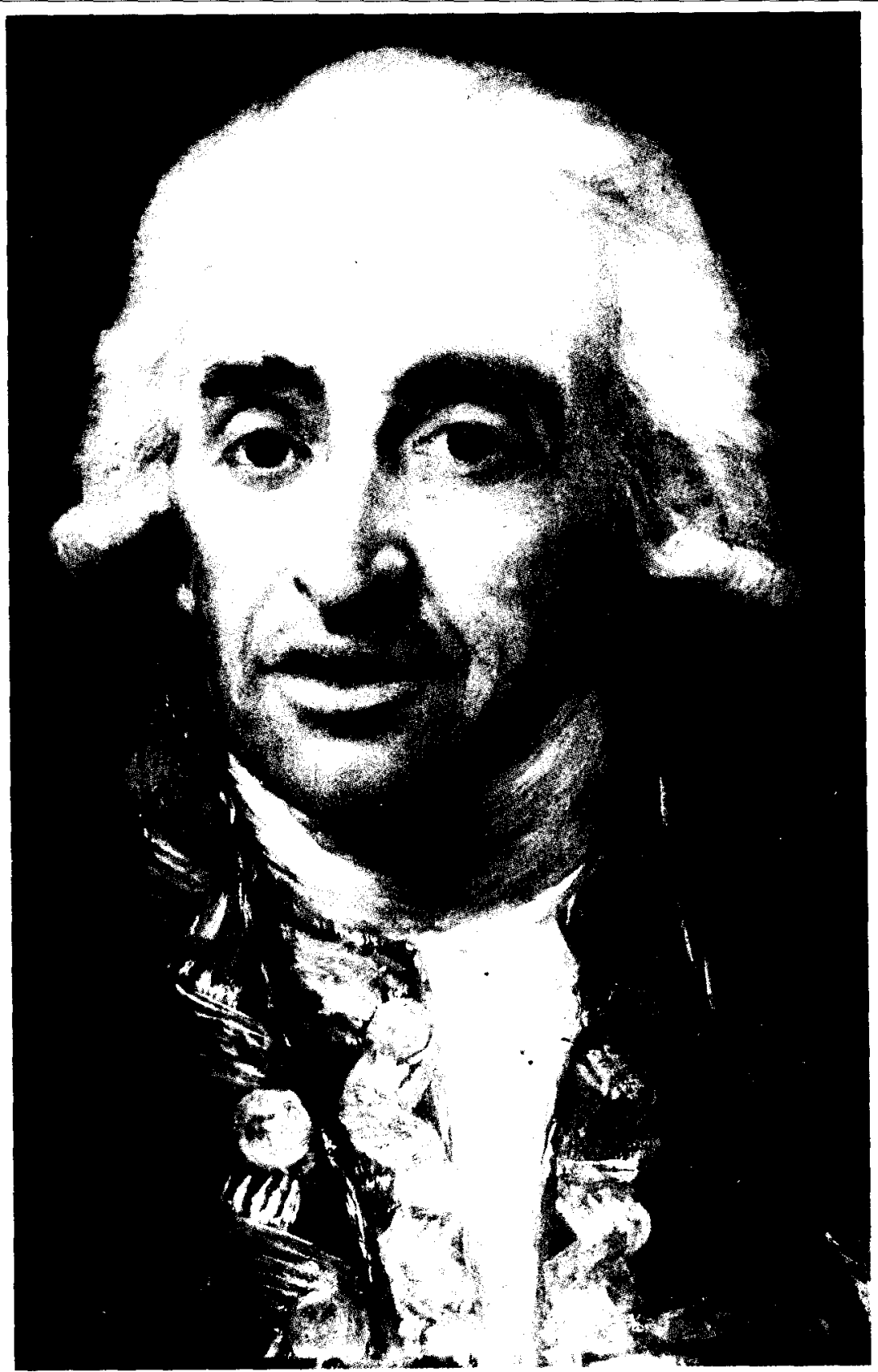

Fig. 1: Goya y LuCIENTES, Francisco de, Juan de Villanueva. Detalle. Madrid, Museo de la Real Academia de Bellas Artes de San Fernando. 
Artes ${ }^{1}$. La labor intensa de la Junta de la Comisión de Arquitectura mantuvo excesivamente ocupados a los arquitectos, quienes se vieron en la obligación de realizar una continua, extensa y profunda tarea de revisión, corrección, aprobación, reprobación y hasta de nuevo diseño de proyectos y expedientes con sus correspondientes memorias arquitectónicas y económicas de obras nuevas remitidos desde los lugares más dispares de España ${ }^{2}$. A todo ello hay que añadir aqui la actividad docente cotidiana, que hacia necesaria una dedicación más práctica que teórica, acomodándose a las diversas circunstancias de cada momento, asi como la realización de proyectos y de obras particulares de cada uno de ellos.

Pero con ser responsabilidad de los profesores arquitectos tales reformas no se les puede atribuir plenamente el relativo fracaso de los planes de estudios ${ }^{3}$. Sin capacidad de decisión, que correspondia a la junta particular de la Academia, su labor bien intencionada consistia en hacer un simple, pero importante, asesoramiento técnico, que después era estudiado en dicha junta, siendo sus informes aprobados o rechazados por ella y en última instancia por el mismo rey. Por tal motivo los arquitectos reclamaron en esta época - sobre todo en su respuesta inquietante al discurso hiriente de Varas - de una forma más o menos encubierta cierta capacidad de decisión, que entonces era ejercida por otros sectores académicos al margen de la docencia y del conocimiento específico y profundo de la teoria y de la práctica artísticas ${ }^{4}$

' Villanueva, J., Informe sobre los estudios en la Academia. Madrid, 20 de julio de 1792. A.A.S.F.: Leg.: 1-18/4. El arquitecto escribió lo siguiente sobre este plurifuncionalismo de la Real Academia de San Fernando: «Me sera forzoso ascender a los principios de este establecimiento que no sé si pueda llamarse Academia, o Escuela de las tres Nobles Artes, pues queriendo ser uno y otro, no me parece cumple algunos de los fines que se propone, como creo por demostrar» (f. 1 ). Más adelante añadiria: "Convengamos antes de todo en dar término a nuestra Academia. Si ha de ser únicamente tal séalo a ejemplo de otras: conferiéncese sobre todos los ramos de las Artes y produzcánse obras y escritos que nos instruyan» (f. 13 anv.). Este tema lo traté en "Juan de Villanueva y los planes de estudio de Arquitectura (1786-1793)». Texto al catálogo de la exposición titulada "Renovación, crisis, continuismo. La Real Academia de San Fernando en 1792". Madrid, Real Academia de BeIlas Artes de San Fernando, 1992.

${ }^{2}$ Sobre la Comisión de Arquitectura de la Real Academia de San Fernando: Garcia MELERO, J. E., "Arquitectura y burocracia: el proceso del proyecto en la Comisión de Arquitectura de la Academia (1786-1808)m. Espacio, Tiempo y Forma, serie VII, núm. 4. Madrid, Facultad de Geografia e Historia de la U.N.E.D., 1991, págs. 283-347.

${ }^{3}$ Los planes de estudio de la Real Academia de San Fernando hasta el año 1800 han sido analizados a un nivel general en el espléndido libro, que incluye una documentación inédita muy valiosa, su tesis doctoral, de ÚBEDA DE LOS CoBos, A., Pintura, mentalidad e ideología en la Real Academia de Bellas Artes de San Fernando. 1741-1800. Madrid, Servicio de Reprografia de la Universidad Complutense, 1988. 2 vols.

${ }^{4}$ Villanueva, J.; Arnal, P.; Martin Rodriguez, M.; Sanchez, F. y Machuca y Vargas, M.: Res- 
Hay que añadir a todo esto las luchas intestinas en el seno mismo de la Academia, las pugnas entre un estamento directivo y político, los consiliarios, de configuración aristocrática, propia del Antiguo Régimen, y otro profesional, de profesores de las Bellas Artes, sobre el cual pesó la mayor actividad, que en cierta forma parecen representar a la naciente burguesía decimonónica. Pero también hubo debates y diferencias entre los directores y tenientes directores de los distintos ramos de las Bellas Artes, y de una forma especial entre los arquitectos y los matemáticos, manifiestos en su polémica de 1793 con Antonio de Varas ${ }^{5}$. Hay que recordar aqui, que fue precisamente un catedrático de Matemáticas, Benito Bails, quien por fin publicó un libro útil para el estudio de la Arquitectura civil, despues de varios intentos inexplicablemente fracasados de los arquitectos al presentar los textos realizados a la censura del estamento directivo ${ }^{6}$. Se justificó esta reprobación con el asesoramiento de otros organismos culturales del pais al margen de la Academia?.

Parece imprescindible el referirse aqui a las diferencias existentes entre los profesores de Arquitectura y Juan de Villanueva, su Director General entre 1792 y 1795 . Esas discrepancias se materializarian en su interesante informe reservado, muy significativo, del 20 de julio de 1792

puesta de los arquitectos al Discurso del matemático Antonio de Varas. Madrid, 17 de enero de 1793. A.A.S.F.: Leg.: 18-20/1. En este sentido se dice en este documento: “Veneramos como humildes vasallos en lo intimo de nuestros corazones las ordenes del Soberano: obedecemos resignados, y humildes postramos nuestros particulares conocimientos a sus Leyes, a sus Estatutos, y a sus preceptos: el cumplir las obligaciones que se nos han impuesto es toda nuestra mira y ocupación. Se nos pregunta como artistas, y respondemos según nuestro entender. Si proponemos con uniformidad o variedad, no determinamos, no elegimos, ni mandamos; cumplir y obedecer es nuestro empleo, y del sabio y celoso Cuerpo de los Sres. Viceprotector, Consiliarios, Académicos de honor y el Secretario, reunidos en la Junta particular por los Estatutos, debe dimanar todas las resoluciones, todas las determinaciones, y todos los Acuerdos. A este poderoso Cuerpo debió únicamente dirigir nuestro Catedrático sus instancias, sus solicitudes, los fines que indica, y reclama en su Escrito, reducidos a que se enseñen las Matemáticas, la Fisica y todo el completo de conocimientos que señala en su papel" (fols. 11 anv. y rev.).

${ }^{5}$ Varas, Antonio de, Discurso en la Academia. Precedido por una carta al viceprotector. Madrid, 9 de octubre de 1792. A.A.S.F.: Leg.: 18-20/1.

${ }^{6}$ BAlls, B.: Elementos de Matemáticas. Madrid, Joachin Ibarra, 1779-1787, en 12 vol.

${ }^{7}$ En el archivo de la Real Academia de San Fernando se encuentran varios manuscritos de Juan Pascual Colomer en los que se estudian los problemas habidos con la redacción del curso de Arquitectura de la Academia: Informe sobre el estado de la arquitectura. 29 de mayo de 1815. A.A.S.F.: 1-25/4.-Informe sobre los trabajos de la Academia desde su fundación. 16 de junio de 1815. A.A.S.F.: 1-25/4.-Resumen de los hechos en relación con la arquitectura acaecidos en la Academia. 7 de marzo de 1835. A.A.S.F.: 1-25/4.-Informes sobre los trabajos de la Academia desde su fundacion, relativos a arquitectura. (s.f.) A.A.S.F.: 1-25/4. Toda esta documentación la publicó ÚBEDA DE LOS CoBos, A., en su libro titulado Pintura, mentalidad e ideologia..., op. cit.., vol. II, págs. 656-734. Su estudio es básico para conocer los libros de texto de este organismo. 
dirigido a Bernardo de Iriarte, el inteligente y timorato viceprotector de este organismo.

Tal disparidad de opiniones posiblemente se debiera a las funciones diferentes, aunque en cierta forma paralelas y convergentes, realizadas por el arquitecto del rey y los maestros de la Academia. Este centro de las Bellas Artes también estaba bajo el patronazgo del monarca; pero las actividades de sus profesores, que al mismo tiempo eran constructivas y pedagógicas, y teóricas y prácticas, abarcaban a todo el Reino. Sin embargo, el arquitecto real se ocupaba de las obras promocionadas directamente por el rey. Su vínculo con la realeza era, asi, inmediato, mientras que la relación de los profesores con ella resultaba, por lo general, indirecta, pues se hacia casi siempre a través de la Academia y de ésta con Carlos IV por medio de su protector. La cercanía del arquitecto real con el monarca y, asímismo, la mayor importancia representativa entonces y hasta económica de sus construcciones le daban más poder y prestigio; pero al mismo tiempo su área de influencia territorial era en cierto modo bastante menor, limitándose casi siempre a los sitios reales. De esta forma se podria decir aqui que, mientras que los arquitectos de la Academia cumplian una misión más democrática, al ocuparse de una diversidad de obras promovidas por muy diferentes patronazgos, la del arquitecto del rey era más selectiva y totalmente aristocrática. La proximidad física al poder máximo le prestigiaba; pero sin cumplir una tarea especificamente docente en el concepto institucional de este término, que acrecentaba, o asi parecia hacerlo, su consideración teórica.

Quizá sea posible percibir en esta polémica promovida por Juan de Villanueva una lucha por conseguir un poder mayor y del mismo modo una disparidad de objetivos entre la vinculación directa del uno con el soberano a través de las obras reales y de los otros con la idea de Estado, aún con dependencia más o menos indirecta por medio de todo un organismo con ese mismo rey, dada la configuración absolutista de la Monarquía. Resultaba entonces problemático el discernir, asi, dentro de la típica escala jerárquica tan manifiesta en esta época y que la define, la superioridad efectiva del arquitecto de Carlos IV sobre los de la Academia, que, por otra parte, controlaban, o así parecía o querian que fuese, toda la práctica arquitectónica del pais, lo cual era cuantitativa y cualitativamente demasiado importante.

Habia, por lo tanto, un equilibrio inestable y ambiguo, que precisamente se rompió al ser nombrado Juan de Villanueva Director General el 29 de mayo de $1792 \mathrm{y}$, por lo tanto, superior jerárquico de los otros ar- 
quitectos dentro de la misma Academia ${ }^{8}$. Ocasión que éste aprovecharia para manifestar todas sus discrepancias con ellos con motivo del intento del plan de estudio de 1792 y la petición, que el viceprotector le hizo, de un informe sobre la situación de los estudios artisticos en este organismo. Su crítica se centró en la actividad de la Comisión de Arquitectura, que era, sin duda, el servicio que diferenciaba a los arquitectos de los demás artistas, singularizándoles, y que les proporcionaba más poder, más prestigio y también quizás hasta más dinero ${ }^{9}$.

\section{MALESTAR Y CRISIS ACADÉMICA EN EL ENTORNO DE 1792}

El año 1792, y su entorno cronológico, tuvo un gran interés en la vida académica, porque durante su transcurso ocurrieron una serie de acontecimientos muy importantes y significativos, que produjeron una crisis profunda de valores en el seno mismo de la Academia. Tal vez sea posible percibir ya entonces el inicio de la ruptura de algunos de sus artistas más destacados con el clasicismo, al poco tiempo de asentarse, como lenguaje único e inequivoco y diversificarse en distintos dialectos. Estas variaciones facilitarian la irrupción de una nueva mentalidad liberalizadora ya claramente prerromántica bajo la sombra del historicismo de diverso sino.

Éstas fueron precisamente las actitudes similares sostenidas por Francisco de Goya (fig. 2) y Juan de Villanueva, las personalidades más brillantes del arte español de este momento de tránsito entre siglos, que podrian considerarse como los artistas más singulares y hasta heterodoxos de una Academia jerarquizada y protocolaria en algo bastante mediocre y gris, pero que cumplia una función importante. Ni el uno ni el otro se sintieron bien acogidos y cómodos en este organismo, al que acabarian abandonando. Egocentristas y geniales fueron aplastados por el

${ }^{8}$ Juan de Villanueva fue propuesto para el cargo de Director General en la junta general del 25 de mayo de 1792. En la junta ordinaria del 3 de junio de 1792 se notificó que de orden de S. M. del 29 de mayo se nombró a este arquitecto para dicho puesto para el trienio siguiente A.A.S.F.: 3/85, f. 202.

9 VILlanueva, J., Informe. 20 de julio de 1792. A.A.S.F.: Leg.: 1-18/1. Juan de Villanueva escribio el 24 de agosto de este mismo año otro informe sobre los Descartes de la muchacheria en la Academia. A.A.S.F.: Leg.: 1-18/1. En este legajo se hallan el original y una copia de este documento, así como una serie de cartas que envió al viceprotector Bernardo de Iriarte y de éste a áquel. Están datadas el 20 de Julio de 1792 (de Villanueva a Iriarte), el 27 de ese mismo mes y año (de Iriarte a Villanueva), el 16 de agosto (de Villanueva a Iriarte), el 27 de agosto (de Villanueva a Iriarte), y el 28 de agosto (de Iriarte a Villanueva). 


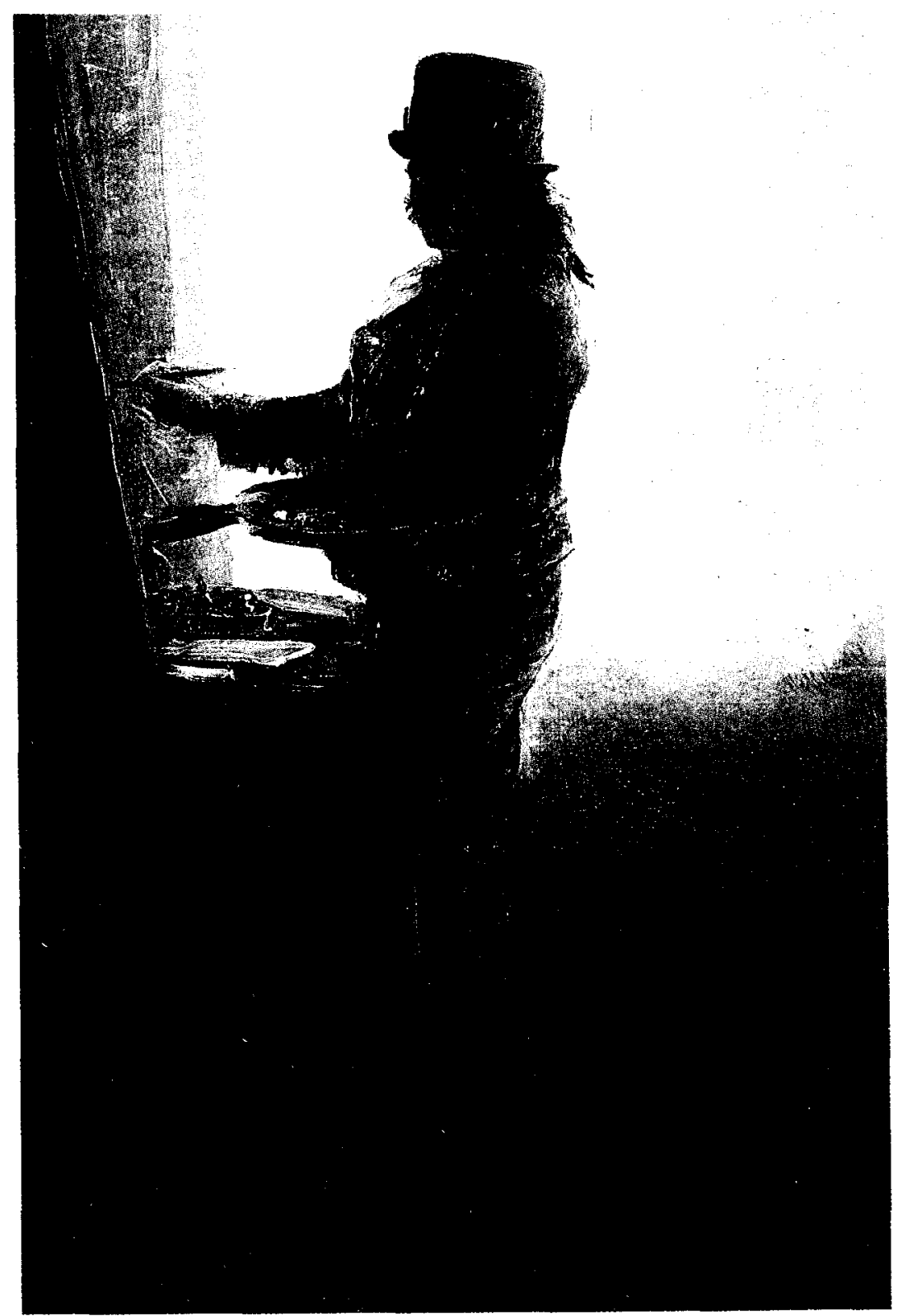

Fig. 2: Goya y LuCIENTES, Francisco de, Autorretrato en su estudio. Hacia 1780-1795. Oleo sobre lienzo. Madrid, Real Academia de Bellas Artes de San Fernando. 
peso de esa anónima y hasta en cierta forma uniforme mediocridad impersonal tan generalizada, que, por lo demás, era totalmente precisa imponer para lograr realizar los objetivos académicos. Así, pasaron por ella acallados y hasta atados por las circunstancias, como estrellas fugaces casi desapercibidas. Goya lo hizo poco menos que en total silencio y con una discreción bien humilde, mientras que Villanueva se mostró mucho más bullicioso y peleón, siempre que pudo ${ }^{10}$. No dejaron prácticamente ninguna huella significativa en este centro a no ser la inquietante y vivencial polémica tras de si, tal y como hiciera el complejo arquitecto entre 1792 y 1793, y sus importantes informes educativos, auténticos manifiestos de una actitud critica, pero creativa, hacia la Academia como institución y también un cambio abierto hacia una nueva mentalidad.

La intención de realizar el plan de estudio de 1792 es, sin duda y al mismo tiempo, la causa y el hilo conductor de este instante de tensiones $y$ de crisis profunda ". Todos los acontecimientos académicos importantes de este período ciertamente dificil pasaron por él: desde los revolucionarios informes de Goya y Villanueva, el uno más estético y muy poético y el otro en algo político, hasta el debate de los arquitectos con Antonio de Varas y la prevención temerosa del viceprotector Bernardo de Iriarte hacia estos últimos, a quienes consideraba coaligados y fuertes por la importante función, que estaban desempeñando en la Junta de la Comisión de Arquitectura ${ }^{12}$.

El tema crucial de la revisión de los planes de estudios fue el eje neurálgico, la columna vertebral de esta crisis; pero no se puede consi-

${ }^{10}$ Goya dimitió de su empleo de Director de Pintura de la Academia debido a sus «continuos achaques y especialmente a su profunda sordera". Junta ordinaria del 30 de abril de 1797, f. 76 rev.. Se le pasó a director honorario. Gregorio Ferro le sucedió. Junta ordinaria del 4 de junio de 1797. A.A.S.F.: 86/3.

"Los acuerdos alcanzados en las juntas extraordinarias reunidas para tratar el tema del plan de estudios de 1792 se hallan en A.A.S.F.: leg.: 1-18/11. Dichas juntas se celebraron el 19 de agosto, 14 de octubre y 18 de noviembre de 1792, y 30 de junio de 1793 . El borrador de la del 28 de octubre se localiza en A.A.S.F.: leg.: $\quad$-18/14. El acuerdo de la junta particular de la Academia del 1 de julio de 1792, que convocaba dichas juntas extraordinarias para tratar sobre los estudios de la Academia se halla en A.A.S.F.: leg.: 1-18/7. En este mismo legajo se encuentran el oficio del secretario isidoro Bosarte convocando a los miembros y algunas de las contestaciones de éstos, como la del consiliario Pedro de Silva del 14 de julio, Manuel Martin Rodriguez, Luis Paret, Manuel Salvador Carmona, Benito Bails y Guillermo Casanova.

12 El resumen oficial de la actividad de la Academia durante el trienio comprendido entre el 4 de agosto de 1790 y el 20 de agosto de 1793 se halla en el resumen de las actas de la Academia, redactado por Isidoro Bosarte, su secretario: Distribución de los premios concedidos por el Rey Nuestro Señor a los discipulos de las Tres Nobles Artes hecha por la Real Academia de San Fernando en la junta pública de 20 de agosto de 1793. Madrid, en la Imprenta de la viuda de Ibarra, 1793. B.A.S.F.: C.-896. 
derar como la única causa. Hubo en el entorno de 1792 otros aspectos aparentemente ramificados muy importantes, tal vez pasados por alto en demasiadas ocasiones, y que también sirven para determinar con cierta exactitud el momento. En este sentido se halla el asunto de las actuaciones arquitectónicas en los templos góticos, en donde a la idea de la superioridad del clasicismo sobre este estilo medieval sucede ahora el criterio de conservarlo en sus formas originales para no desacreditar a la Historia del Arte, haciéndola perder uno de sus testimonios más auténticos. Pero ya estaban siendo cuestionados por una parte la dicotomía entre el gótico y el clasicismo, y por la otra el parangón, que había establecido cierta similitud entre esa tendencia bajomedieval y el barroco. Sirva aqui de ejemplo bien significativo la actuación muy criticada de Fernando González de Lara en la Puerta de Santa Maria de la Catedral de Burgos, que la restauró con el uso de un lenguaje clásico, y la reacción historicista de la Junta de la Comisión de Arquitectura en estos mismos años de $1791-1792^{13}$.

A todo ello también hay que añadir aqui el tema siempre jocoserio de la promiscuidad de los asientos en la Academia, una especie de contrarrevolución que acabó metamorfoseando de algún modo los protocolos rígidos de un organismo jerarquizado, estamental y en exceso protocolario. En él el problema americano de las relaciones de este centro con el de San Carlos de México, que ocasionó la oposición de esta Academia a la proliferación en España de otros institutos similares, se unió a la idea de que los profesores arquitectos eran demasiado poderosos. Entonces se debió pensar, que se precisaba acabar con ese poder, para que todo funcionara con la acostumbrada normalidad en algo penumbrosa ${ }^{14}$.

\footnotetext{
${ }^{13}$ Sobre la reforma de la portada principal del templo catedralicio de Burgos en el entorno de 1790 puede verse: A.A.S.F.: Actas de Arquitectura, 1790, 17 de diciembre, f. 153. También en las Actas de la Junta de la Comisión de Arquitectura. Sobre las relaciones a un nivel teórico y práctico entre el clasicismo y el gótico durante la segunda mitad del siglo xVIII pueden verse mis publicaciones siguientes: Garcia MELERO, J. E., "La visión del románico en la historiografia española del "neoclasicismo romántico" ", Espacio, Tiempo y Forma, núm. 2 (núm. 1 de la serie VII). Madrid, Departamento de $H_{.}{ }^{a}$ del Arte de la Facultad de Geografia e Historia de la U.N.E.D., 1988, págs. 139-186. Garcia Melero, J. E., "Bases metodológicas para el estudio de las transformaciones arquitectónicas de las catedrales góticas", El Arte en tiempo de Carlos III. IV Jornadas de Arte. Madrid, Departamento de Historia del Arte "Diego Velázquez", Centro de Estudios Históricos, C.S.I.C., 1989, págs. 125-135. Garcia Melero, J. E., “Espiritualidad y estética: las transformaciones en los exteriores de las catedrales góticas españolas en el siglo XVII!”, Hispania Sacra, vol. 41. Madrid, Centro de Estudios Históricos, 1989, págs. 603-639. Garcia MELERO, J. E., "Realizaciones arquitectónicas de la segunda mitad del sigło XVIII en los interiores de las catedrales góticas españolas". Espacio, Tiempo y Forma, serie VII, Historia del Arte, t. 2, 1989, págs. 223-286

${ }^{14}$ Los problemas protocolarios surgidos en 1793 con motivo de la designación de Cosme
} 


\subsection{La renovación del vértice político de la Academia: convicción clásica y mentalidad prerromántica}

El año 1792 se caracterizó en primer lugar por una amplia y profunda renovación de los puestos principales de este organismo. Los cargos y empleos políticos y administrativos de la Academia, como eran los de protector, viceprotector, secretario, vicesecretario y director general, fueron ocupados en su transcurso por nuevas personalidades de diversa procedencia: políticos como el Conde de Aranda y Manuel Godoy, Duque de Alcudia (fig. 3), literatos cual Bernardo de Iriarte e Isidoro Bosarte y los artistas el pintor Luis Paret y el arquitecto Juan de Villanueva. A ellos hay que añadir a un noble, el Marqués de la Espeja, designado consiliario, que en 1803 sustituyó a Iriarte en su puesto, iniciando un nuevo intento de reforma de los planes de estudios de este centro bajo la experiencia de los de su predecesor ${ }^{15}$.

Obviamente, tal y como por lo general suele suceder, esta renovación propiciaria la idea de realizar profundos cambios en las estructuras mismas de la Academia y, sobre todo, en el plan de estudio, uno de los cauces más lógicos para llevarlos a término. No obstante, el deseo de renovación debió chocar casi frontalmente con la inexperiencia de estas personalidades en la función a desempeñar en sus respectivos cargos, y hasta es muy posible, que motivara el fracaso de esta idea. Tampoco resulta extraña la actitud conservadora en una cierta mayoria de quienes ejercian entonces la enseñanza, que, aún deseando el cambio, tienden a la inercia por el peso de la costumbre. También pesaría el paso rápido del experto Conde de Aranda por el protectorado de la Academia, ya que tan solo estuvo en él entre el 24 de enero y el 15 de noviembre de 1792. Sin embargo, el rey trató de salvar de alguna forma esa inexperiencia designando al experimentado Antonio Ponz, que falleceria precisamente este mismo año, el 4 de diciembre, como asesor de Bosarte y Paret en sus puestos respectivos de secretario general y de la Junta de la Comisión de Arquitectura al tiempo de ser nombrados ${ }^{16}$.

Acuña como director de los discipulos de la Real Academia de San Carlos en México pensionados en Madrid los traté en el libro que coordiné: Garcia Melero, J. E., "Nexos y mimesis academicistas: América en la Academia de Bellas Artes de San Fernando", cap. IV del libro Influencias artísticas entre España y América. Madrid, Fundación Mapfre América, 1992, págs. 259-359. Se basa en los legajos del A.A.S.F.: 36-3/2, 48-1/1, 85-3 y 4-9/1.

${ }^{15}$ El informe del Marqués de Espeja, presentado en la junta particular del 20 de marzo de 1803, en el cual expuso el estado actual de los estudios de la Academia, haciendo ver lo que les faltaba para el complemento de la enseñanza, se halla en: A.A.S.F.: Leg.: 1-49/ 11.

${ }^{16}$ Oficio del Conde de Floridablanca, protector de la Academia, dirigida a Antonio Ponz, 


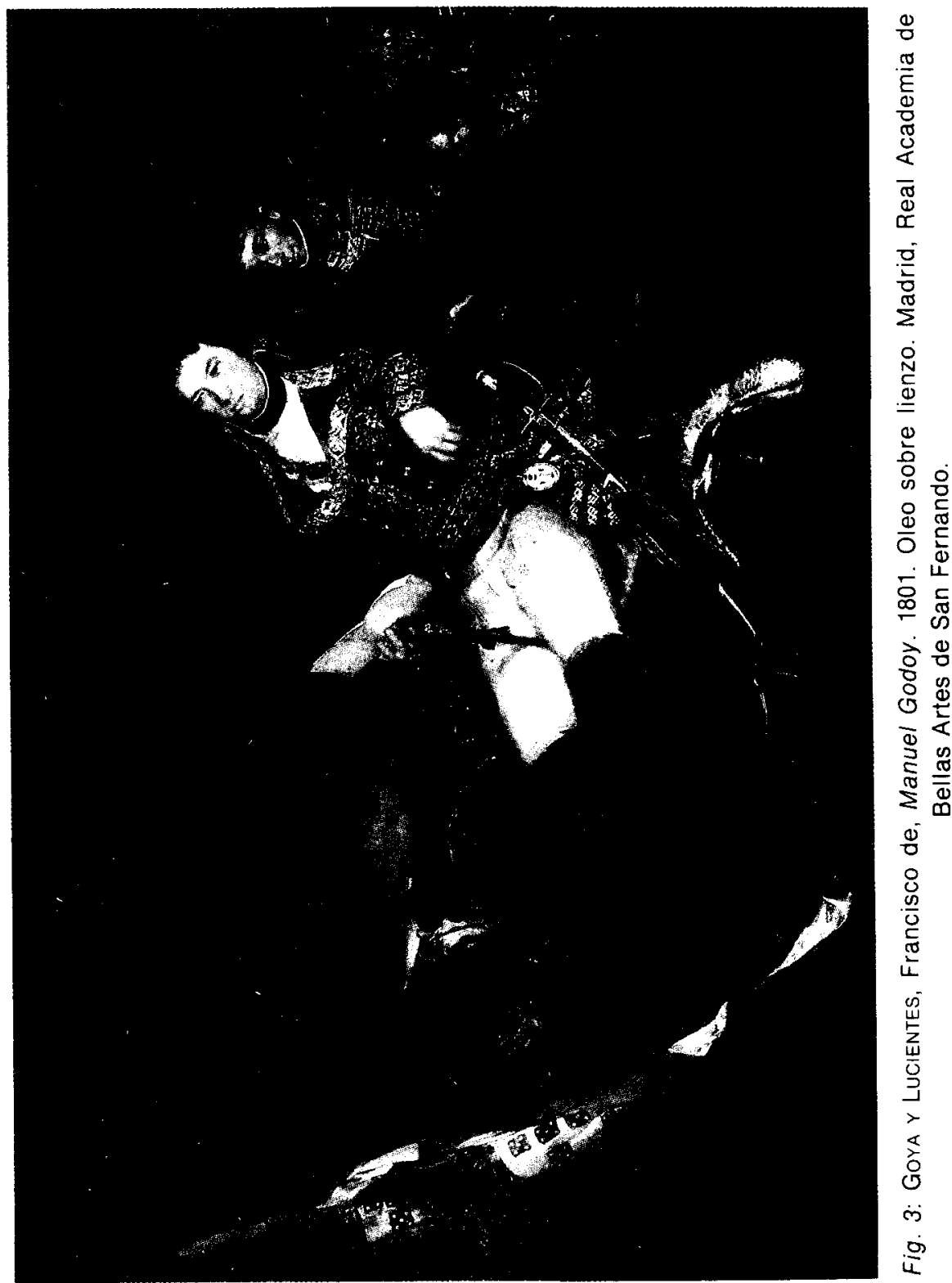


Una nueva generación de personajes muy distintos y muchos de ellos inexpertos en la vida académica, pero esperanzada, sucedía ahora a otra, que habia ido poco a poco desapareciendo al ser sustituida en sus cargos respectivos y, también, por las defunciones siempre inevitables. Hay, así pues, una reacción de algún modo lógica del nuevo equipo, que llega al poder con la idea de realizar una renovación en busca de la modernidad, pero partiendo siempre de la tradición hallada. Podemos calificar a esta reacción de generacional por denominarla de alguna forma, pues no habia un contraste muy significativo de edades entre ellas. Seria el equipo que, al llevar, o al intentar hacerlo, al clasicismo a su cima más alta, propiciaria también su crisis por demasiado celo y por exceso al diversificar de un modo historicista sus códigos lingüisticos, buscando su perfección.

Estos miembros, junto con Goya y Juan de Villanueva, fomentaron una forma nueva de ser y de sentir, en el término que Baudelaire dio al romanticismo histórico. Alrededor suyo, en este entorno de 1792, se creó un creciente malestar indefinible por la concurrencia de numerosos aspectos, que incidieron en una serie de luchas intestinas estamentales y en una actitud crítica en la Academia. Si las formas artísticas seguian siendo predominantemente clásicas, aún abriéndose hacia un neomanierismo, un clasicismo diverso de corte post-renacentista, demasiado recreado e intelectualizado en exceso, la actitud, la desazón, era ya romántica y quizás hija de 1789 con todas sus complejidades.

Tal vez los historicismos clasicistas, la visión de la antigüedad, la interferencia del renacimiento y la propia recreación, se habian sucedido demasiado vertiginosamente en muy pocos años, estratificándose y/o entremezclándose, no siendo plenamente asimilados y hasta confundiéndose con otros historicismos no ortodoxos de épocas bien distintas y distantes. Habia, asi pues, demasiado desconcierto teórico al pasar de un único código, el vitruviano, cotejado muchas veces sin casar con la imagen pragmática de las ruinas, a una diversidad de ellos con la divulgación de los tratados renacentistas, y las ideas racionalistas y hasta funcionalistas de la época ${ }^{17}$. Su conjunción en algo laberintica, al pasar de la

comunicándole los deseos del rey Carlos $N$ de que asesorara a Bosarte y Paret en el ejercicio de sus nuevos cargos. Palacio, 24 de enero de 1792. A.A.S.F.: 1-39-7. Con la misma fecha se comunicó a Isidoro Bosarte y a Luis Paret sus nombramientos respectivos como secretario y vicesecretario (secretario de la Comisión de Arquitectura) de la Academia.

${ }^{17}$ Una visión conjunta de las ediciones españolas del tratado de Vitruvio de 1582, de 1761 y 1787 las ofreci en: Garcia Melero, J. E., "Las ediciones españolas de "De Architectura" de Vitruvio", Fragmentos. Madrid, Ministerio de Cultura, núms. 8 y 9, págs. 102-131. En este artículo se cita una bibliografia amplia sobre el particular. En el catálogo de la 
unidad y uniformidad a la diversidad y pluriformidad, era un auténtico nudo gordiano difícil de desatar y complejo de entender en nuestros días.

No bastaba, con que se esgrimieran esos mismos postulados clasicistas contra los vestigios barrocos, aún no desaparecidos totalmente. Se insistia en ese clasicismo muchas veces tal vez más por rutinaria costumbre con algo de burocracia y hasta por el interés de ejercer con su uso un poder económico y de prestigio, que por una convicción auténticamente real. El fenómeno, lo acaecido en este entorno cronológico del revolucionario año de 1789, es realmente muy complicado, y de dificil y exacta interpretación; pero parece marcar el inicio de una crisis de identidad y la aparición de un malestar, de una zozobra, de una nueva forma de ser, pre-romántica. Tal vez el nuevo clasicismo de hacia 1750 hubiera nacido ya enfermo al ser considerado desde esta perspectiva y su vivencia demasiado escueta fuese utópica como único código. La idea auténtica es más la de un historicismo, que en la segunda mitad del siglo de la llustración quiso ser clásico, o tuvo esa vocación, que la de un neoclasicismo en toda la extensión de este concepto.

El tal vez espejismo del clasicismo español de la segunda mitad del siglo XVIII, surgido desde el medio académico, acabó siendo demasiado tiránico. Era un estilo, pero también una forma peculiar de vida, aparecida bajo una ambigua y muchas veces equivoca idea social del progreso, fundamentalmente retrógrados, pues beneficiaba a determinados estratos sociales bajo la mágica fórmula de ilustrar al pueblo en el arte verdadero. Quizás sea posible calificar a este proceso cultural borbónico de contrarrevolución artística, pues privaba a la práctica del arte de la variedad y diversidad necesarios en todo proceso de creación. Bajo su nombre y también bajo un racionalismo despótico excesivo, en ocasiones caricaturesco, se quiso controlar, encorsetar y encadenarlo todo, despojando al artista de la necesaria libertad creativa so pena de caer en la heterodoxia, que se materializaba en su persecución, aislamiento y desprestigio.

exposición La Real Academia de San Fernando en 1792 incluí una relación comentada de los libros publicados en España entre 1786 y 1796 junto con la reseña de los principales documentos de la época, en este entorno de 1792, sobre arte, que proporcionan la idea de la diversidad de códigos empleados entonces en el mundo académico y extraacadémico. Hay textos apropiados para la Academia y otros publicados en función de la pervivencia de los gremios y de la existencia de los maestros de obras. 


\subsection{El creciente poder de los arquitectos y la critica a la Comisión de Arquitectura.}

Entre 1786, fecha de la creación de la Junta de la Comisión de Arquitectura, y 1792, año de revisión del plan de estudio y de malestar y crisis, los arquitectos consiguieron adquirir más poder y más prestigo como consecuencia de la aparición de este servicio, derivado de las reales cédulas de 1777, y de su gran actividad. La casi masiva cantidad de proyectos censurados y las obras planeadas por los arquitectos integrantes de esta junta certifican su capacidad de control y de decisión. Asi, en el trienio comprendido entre 1790 y 1793 este servicio habia gestionado mil treinta y dos inspecciones, informándose doscientos cincuenta y un expedientes de todo tipo de edificios, y setecientas treinta y un planos o diseños de obras. También se habian hecho treinta informes pedidos por varios tribunales de dentro y fuera de Madrid, nombrándose en veinte ocasiones arquitectos para la formación de nuevos planos de obras públicas ${ }^{18}$.

En 1792, año en el que se designó a Juan de Villanueva Director General de la Academia, eran Directores de Arquitectura Pedro Arnal y Manuel Martín Rodríguez, y Tenientes Directores Francisco Sánchez y Manuel Machuca y Vargas. Todos ellos estaban muy ocupados con la actividad de la Junta de la Comisión de Arquitectura, realizando importantes proyectos individuales, derivados en una gran parte de su misma condición de miembros integrantes de estas reuniones ${ }^{19}$.

${ }^{18}$ Expedientes y diseños concernientes a obras públicas que ha reconocido y despachado con los correspondientes dictámenes la Junta de Comisión de Arquitectura de la Real Academia de Nobles Artes desde principios de agosto de 1790 hasta fines del mismo mes en el presente año de 1793. A.A.S.F.: Leg.: 28-1/5. Se hace referencia a este documento en las Actas de la Junta ordinaria del 8 de septiembre de 1793. A.A.S.F.: 3/85, fol. $264 \mathrm{rev}$. Bosarte recogió esta información en su resumen de las actas de la Academia desde el 20 de agosto de 1793 hasta el 13 de julio de 1796. Distribución de los premios concedidos por el Rey Nuestro Señor a los discipulos de las Tres Nobles Artes hecha por la Real Academia de San Fernando en la junta pública de 13 de julio de 1796. Madrid, en la Imprenta de Ibarra, 1796. B.A.S.F.: A-257. Véase la pág. 20.

${ }^{19}$ En este sentido véase mi artículo: Garcia Melero, J. E., "Arquitectura y burocracia: el proceso del proyecto en la Comisión de Arquitectura de la Academia (1786-1808)'. Espacio, Tiempo y Forma, serie VII, Historia del Arte, t. 4, 1991, págs. 283-348. Obra muy importante y valiosa para el estudio de esta Comisión de Arquitectura es: SAmbricio, C., La arquitectura española de la llustración. Madrid, Consejo Superior de los Colegios de Arquitectos de España, Instituto de Estudios de la Administración Local, 1986. En este libro, sintesis de los importantes artículos de este autor sobre el contenido teórico-práctico de la arquitectura española de la segunda mitad del siglo XVIII, se halla la cita de la documentación y de los dibujos sobre proyectos, que pasaron por esta Junta de la Comisión de Arquitectura. 
La critica hacia los arquitectos tuvo entre 1792 y 1793 tres momentos distintos: el informe de Juan de Villanueva del 20 de julio de 1792 sobre los estudios en la Academia ${ }^{20}$; el Discurso pronunciado por el segundo Director de Matemáticas Antonio de Varas en la junta del 28 de octubre de ese mismo año ${ }^{21} ;$ y, finalmente, la carta de Bernardo de Iriarte, el Vice-protector, dirigida al Protector, entonces el Duque de Alcudia, en abril de 1793 con motivo del problema suscitado por el asiento que Cosme Acuña, Director de la Real Academia de San Carlos de México y también de los pensionados de ese centro en la Corte, debia ocupar en las juntas de la Academia ${ }^{22}$. Eran tres motivos distintos aprovechados por algunos con torpe habilidad para tratar de destacar su creciente poder, considerado injustificado, y la necesidad de tomar medidas correctivas. De todas ellas los arquitectos salieron airosos; pero con la crisis se produjo un cierto desprestigio de la Academia como institución y, quizás, el hecho mismo de que el plan de estudio, que se gestaba entonces, no progresara.

\subsubsection{Critica y escepticismo en Juan de Villanueva}

Juan de Villanueva criticaria en su informe del 20 de julio de 1792 con toda dureza la actividad de la Junta de la Comisión de Arquitectura, creada por Carlos III, a un doble nivel general e individual, porque "no es lo que se deseaba, ni lo puede ser» (figs. 4 y 5 ) $^{23}$. En su opinión, y esta acusación resultaba realmente comprometida y conflictiva, en este servicio académico se cometian demasiados abusos, pues los profesores eran propensos a atribuirse comisiones, que les tenian ocupados y les producian ganancias, en lugar de "demostrar los desaciertos y en enseñar el

${ }^{20}$ Villanueva, J., Informe sobre los estudios de la Academia. Madrid, 20 de julio de 1792. 36 fol. A.A.S.F.: 1-18/1.

${ }^{21}$ VARAS, Antonio de, Discurso. Madrid, 9 de octubre de 1792. Leido por el propio Varas en la junta del 28 de octubre de 1792. A.A.S.F.: Leg.; 18-20/1.

${ }^{22}$ IRIARTE, B. de, Borradores de su carta dirigida al protector de la Academia Duque de Alcudia. Madrid, abril de 1793. 3 borradores. A.A.S.F.: 48-1/1.

${ }^{23}$ Villanueva, J., Informe sobre los estudios de la Academia. Madrid, 20 de julio de 1792. A.A.S.F.: 1-18/1, fol. 29. Con la misma fecha Juan de Villanueva remitió una carta al viceprotector Bernardo de Iriarte en la que le decia: «Muy Señor mio: Como ofreci a $V$. S. remito ese Escrito que después de mi ascenso a Director General he formado en Aranjuez. V. S. le verá y de él hará el uso que mejor le parezca en inteligencia de que si en algo le agrada, y fuese necesaria más explicación en algún punto, estoy pronto a decir cuanto entienda con más extensión, en obsequio de V. S. y de las honras que merezco a la Academia. Dios guarde la vida de V.S. muchos años como deseo. Madrid, 20 de julio de 1792." 
JOSE ENRIQUE GARCIA MELERO

$$
\text { S. Y.S. }
$$

1

I::V0

[EIELIOTECA

$18-1 / 1$

()

Nuy señor mino: 1. S. escusará

me tome la licencia gue $m$ intiera tanido sin haver mexe- Cido La honrra gue acauro cet Fecivir de Onuevera Keal Atcan - Denia , y los Estadutor De éca no me impruciesen la OHigacion De exponer guants entionda? opoxtuns in beneficio cela enveñama puttica, ymagra luntre ce Tro Cuerpo. We será formo menor is los principios Cecios ensablecion

Fig. 4: Villanueva, Juan de, Informe sobre los estudios en la Academia. Madrid, 20 de julio de 1792. Fol. 1 anv. A.A.S.F.: Leg.: 18-1/1.

226 
Los origenes académicos del romanticismo histórico español: malestar...

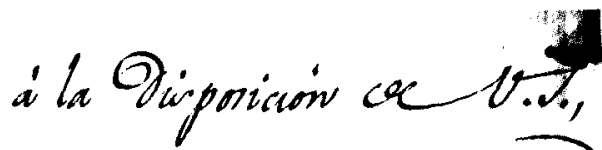

y Tucgo a: Oió le quarde

muchor $\overline{\text { and }}$. Maxid 2or

celfulio a 1792.

$$
\begin{aligned}
& \text { r.ic::yo } \\
& \text { BIELIOTECA } \\
& 181 / 1
\end{aligned}
$$

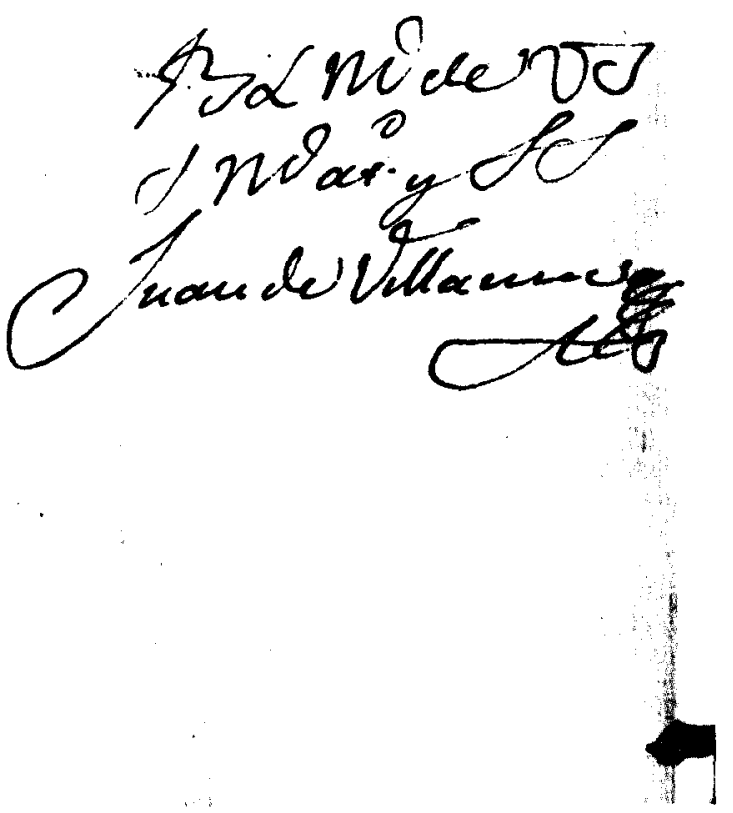

Fig. 5: Villanueva, Juan de, Informe sobre los estudios en la Academia. Madrid, 20 de julio de 1792. Firma y rúbrica del arquitecto. A.A.S.F.: Leg.: 18-1/1.

227 
camino para enmendarlos" ${ }^{24}$. Asi, discrepaba de los nombramientos de profesores para realizar obras fuera de la Corte, ocasionando muchos gastos con sus desplazamientos para visitar el lugar, en donde se tenían que construir los edificios, para poder informar necesariamente de sus circunstancias peculiares ${ }^{25}$.

El arquitecto del rey consideraba la actitud de la Comisión «despótica", palabra que también Goya habia escrito en su informe y que en cierta forma entonces mejor definia a la Academia en general como institución ${ }^{26}$. Hay en él una implícita llamada a la concesión de una cierta libertad, nueva aspiración, que se debia dar a sus académicos de mérito, examinados, aprobados y honrados por este organismo; pero que eran después juzgados de nuevo y corregidos por esa junta al tener que presentar obligatoriamente sus proyectos. Se mostró partidario de que los enviaran siempre o de un modo voluntario o porque los dueños de las obras quisieran hacerlo asi.

Villanueva parece añorar en su informe -en el cual se transparenta un carácter, que, como su arquitectura, es rico en contrastes entre luces y sombras-sobre los estudios de 1792 la situación anterior a 1786, fecha de la fundación de la Comisión de Arquitectura. En su opinión todo proyecto arquitectónico tenia que juzgarse conjuntamente por los profesores de las distintas artes en las juntas de la Academia y no en exclusiva por los arquitectos. Hay, asi pues, en su afirmación la implicita idea de la precisa conjunción de las tres artes entre si.

Pero, sin duda, lo más sangrante de sus juicios es la crítica hiriente, quizás una difamación tal vez injustificada, hacia sus propios compañeros, los arquitectos de la junta, a quienes acusó de aprovecharse de la

${ }^{24}$ Ibidem, fol. 29 rev.-30 anv. Juan de Villanueva escribió sobre este punto lo siguiente: “Hablando con la veneración que debo de aquellas ordenes, diré tan solo, que la junta no es lo que se deseaba, ni puede ser, y que no habiendo procedido una sólida y completa enseñanza no puede pedirse a los Profesores obras dispuestas con acierto, ni menos puede juzgarse de su mérito, y de sus errores con la proligidad que se requiere en la reunión de unas voluntades más bien propensas a tirarse hacia si las Comisiones que les pueda producir ocupación y ganancias, que a demostrar los desaciertos, y enseñar el camino de enmendarlos. Haga V. S. por acercarse a conocer los abusos que hay en esta parte; pues yo absteniendome de manifestar algunos que hacen poco honor al Cuerpo Académico, tan solo diré que en el tomarse la Junta la facultad de juzgar y corregir aún a los mismos académicos de mérito, advierte o cree advertir el público el Despotismo a que, en su concepto. aspiran; y no me persuado que esta fuese la voluntad de $\mathrm{S}$. M., pues, ¿a qué examinar aprobar y honrar a un profesor para después verse en la precisión de corregirle y sonrojarle?",

${ }^{25}$ Ibidem, fol. 30 rev. -31 anv.

${ }^{26}$ Goya, F. de, Informe sobre los estudios de la Academia. Madrid, 14 de octubre de 1792. 2 fol.. A.A.S.F.: $1-1 / 18$ 
situación para hacerse con los proyectos (figs. 6 y 7). Lo cual documenta la existencia de un profundo desacuerdo entre ellos: entre los profesores de la Academia y el arquitecto del rey con competencias paralelas, pero divergentes. Villanueva no debia sentirse integrado con ellos, sino marginado, y entonces, que era su Director General y, por lo tanto, el superior jerárquico dentro de la Academia, se prestaba a criticarlos ante el Viceprotector, el principal cargo político de este centro de las Bellas Artes. Parecia existir en él bastante resentimiento, acrecentado muy posiblemente por la competencia de Pedro Arnal, quien también se habia presentado al concurso para la provisión del cargo de Director General. Los arquitectos debieron votar a este último, prefiriéndose, así, su dedicación continua a la Academia a la genialidad de Juan de Villanueva, a quien consideraban más vinculado con el rey, que con este instituto. Sin embargo, el resto de los académicos le dieron su voto ${ }^{27}$. El arquitecto de Carlos IV parecía no despertar la confianza plena de sus colegas en este centro; pero, no obstante, gozaba de un gran prestigio entre los otros artistas y los consiliarios.

Villanueva disentia en su informe, una muestra más de su racionalismo, de que un pintor, Luis Paret, fuera el secretario de la Junta de la Comisión de Arquitectura. Pensaba que este empleo siempre deberia ocuparlo un arquitecto ${ }^{28}$. Por este motivo Bernardo de Iriarte en su carta del 27 de julio de 1792 le señaló, que esta crítica podría resentirle, pues, además, ejercia el puesto de secretario segundo de la Academia, supliendo,

${ }^{27}$ Junta ordinaria del 25 de mayo de 1792. Libro de actas. Juntas generales. 1786-1794. A.A.S.F.: $3 / 85$. El expediente de Juan Villanueva como académico se halla en el A.A.S.F.: Leg.: 43-1/1. En este cuadernillo se localizan dos documentos muy interesantes: una autobiografia, en la cual da datos de su actuación en la Academia a petición de Isidoro Bosarte con motivo de la votación para el empleo de Director General, y su noticia necrológica con numerosos datos, de 1811, en plena dominación francesa. En aquella larga carta, fechada el 20 de mayo de 1792, hace el siguiente interesante balance de su actuación en la Academia: "Este es en suma el curso de mis ejercicios, y ascensos en esa Academia; nada diré a Vmd. del mérito que podré haber contraido con ellos: todo el cuerpo no los ignora y las obras que de nueva planta tengo ejecutadas en los Reales Sitios, y esta Corte lo podrán más bien indicar; no menos que el aprovechamiento visible de algunos jóvenes que en medio de mis muchos trabajos, y continuados viajes he podido guiar privadamente en el ejercicio y estudio de la profesión, ya que por el mismo embarazo no me era posible concurrir a la enseñanza pública. Nada más sé qué decir a $V m d$.; y le repito que yo siempre he deseado servir a la Academia, tanto o más que la sirvió mi hermano difunto, pero él y yo hemos sido desgraciados en el concepto que se ha formado de nosotros de malhumorados. A pesar de todo digo con valentía, que el único adelantamiento que se advierte en la parte de diseño en nuestra profesión, aunque no sea de los más esenciales, se debe a nuestro trabajo, y enseñanza; y ojalá se aplicasen los demás a procurar otro tanto en lo que tanta falta nos hace en las demás ramas".

${ }^{28}$ VILlanUeVa, Informe..., fol. 33 anv. 
JOSÉ ENRIQUE GARCIA MELERO

29

Cimmexon is Caxpintexos, como riemper hav sucedido ysucedexá, por gue indrectamente no se saoe puccaver inte Oaño, como seria facil is mi mender.

Ygú posxé Deair à V.J. cel nuevo entablecimiento ve la Junta de Comision Cenroxia), cxiaza à consemencios Ceclat oxbener ce thuevos gifumo hey y veñor $\Phi^{h}$ Carlon texaeno, gue vereo' siempee forventar lacf ctives, yell mayor acicxto cee in obras? Ftatlanio ion $h$ veneracion gue devio oc aguelly or - Dener, giné tansolo gue la Juma no is lo gue de Deseatia, ni lo puede

Fig. 6: Villanueva, Juan de, Informe sobre los estudios en la Academia. Madrid, 20 de julio de 1792. Fol. 29 anv. sobre la Junta de la Comisión de Arquitectura. A.A.S.F.: Leg.: 18-1/1.

230 
Los orígenes académicos del romanticismo histórico español: malestar...

ser, y gue no haviend precedio una Stida, y completa uniwan - za no puede pedines a los Pufiso. - xer obxar Dispuevar con? aciexto, ni meno pued /uzgaswe desw mexito, y detur exia -xes con la proligidad gue fel reguiexe in la Teunion ceconea volunvady mas bien pappensas a tixanes acia si law Comisitg -nes gue les puadar paotucios oat -pacion, y ganowcias, gne á nemontrar lon Oesaciexton, conseñar il Camins ece en - mendaxtos. Hája V.T. po asexcoure a conocer Inabm

Fig. 7: Villanueva, Juan de, Informe sobre los estudios en la Academia. Madrid, 20 de julio de 1792. Fol. 29 rev. sobre la Junta de la Comisión de Arquitectura. A.A.S.F.: Leg.: 18-1/1.

231 
así, al titular en sus ausencias y enfermedades, y en tal calidad estaba capacitado para despachar tanto los asuntos arquitectónicos como los relacionados con las demás artes ${ }^{29}$.

No es de extrañar, por consiguiente, que el viceprotector, deseoso de hacer público este escrito y de emplear sus ideas, lo considerara excesivamente crítico, pareciéndole contener "una u otra especie y expresión que no convendria ni querría $V$. M. sonase en la Junta, donde podría indisponer los ánimos, ofendiendo tal vez a alguno de sus individuos, lo cual sobre producir malos efectos sería contrario a los fines que Vm. se propone en calidad de Director General" ${ }^{30}$.

Por desgracia no ha llegado a nosotros por no haberlo enviado a Bernardo de Iriarte, o tal vez inclusive por no haberlo escrito nunca o terminado a su debido tiempo, el informe prometido y tan deseado de Juan de Villanueva sobre el estudio de la arquitectura en la Academia y su situación en España. De existir este texto tendria una importancia extrema, pues con él se podria conocer mucho mejor su pensamiento teórico sobre este arte y la opinión del autor del Museo del Prado acerca de la forma más adecuada de realizarla a un nivel pedagógico en este centro docente. Sin embargo, escribió un informe sobre los descartes de la muchachería en la Academia, asunto que realmente preocupaba y hasta obsesionaba mucho a los profesores y consiliarios (figs. 8 y 9). A estos escritos de Juan de Villanueva hay que añadir otros dos de un extraordinario interés del año 1781, un original y un extracto, para el estudio de

${ }^{29}$ IRIARTE, B. de, Carta del viceprotector de la Academia dirigida a Juan de Villanueva, su Director General. Madrid, 27 de julio de 1792. 3 fols. A.A.S.F.: 1-18/1. En esta carta Iriarte dice lo siguiente: "Quisiera en ella hacer uso de la representación de V. M., por los fundamentos en que estriba y acertados dictámenes que incluye; pero me parece contiene una $u$ otra especie y expresión que no convendría ni querría $V$. M. sonase en la Junta donde podria indisponer los ánimos ofendiendo tal vez a algunos de sus individuos, lo cual sobre producir malos efectos seria contrario a los fines que V. M. se propone en calidad de Director General. Señaladamente se resentiria don Luis Paret de lo que dice tocante a la Secretaria que ejerce en la Junta de Comisión de Arquitectura y contemplo preciso suprimir tanto más, cuanto Paret es segundo Secretario de la Academia para suplir las ausencias y enfermedades del primero y en aquella calidad puede despachar asuntos de Arquitectura como de las demás Artes".

${ }^{30}$ El 16 de agosto de 1792 Juan de Villanueva volvió a escribir a Iriarte contestando a su carta de 27 de julio de 1792 , en donde el viceprotector le recriminaba algunas alusiones inconsecuentes. En esa carta el Director General dice: “Paso a manos de V.S. el consabido escrito ya enmendado de lo que $V$. S. me advirtió y de alguna otra cosa que tal vez no agradaria a alguno. He dejado parte del párrafo del Secretario, que no me parece puede chocar; y para hacerlo pronto solo he insertado los folios enmendados, dejando los demás; pero con más tiempo, si es preciso, daré a V. S. copia del todo como se hallaba antes, pues en el dia me es imposible de igual letra, por lo mucho que me ocurre hacer en casa". A.A.S.F.: Leg.: 1-18/1. 
Los origenes académicos del romanticismo histórico español: malestar...

2.

pexpetua silo mexeriaren, y

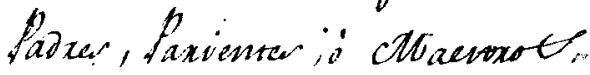

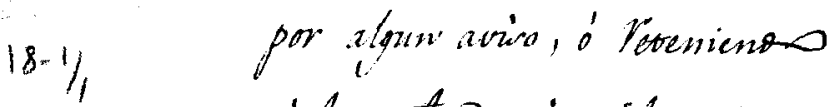

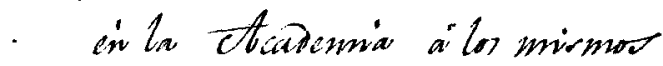

- waichachos, para gue concuxion -Do aguellos in su burca pubieva abvextixely.deta pxovidencia romada por la fuma, a fin se que cavolox ceetha xeso- pieven lon Fovenes, gue con

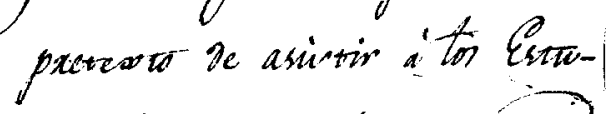

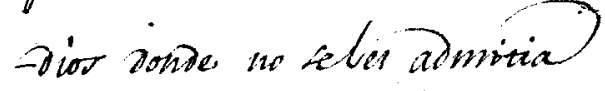
re ocupaxian én kur maxidos, your contravios pexfuticiales $y$ Sexia mi delcaso asi mirmo, gue cumplido il texnino dela

Fig. 8: Villanueva, Juan de, Informe sobre los descartes de la muchacheria. Madrid, 24 de agosto de 1792. Fol. 3 anv. A.A.S.F.: Leg.: 18-1/1.

233 
JOSÉ ENRIQUE GARCIA MELERO

coupaciones to pexmiton para ell tiesmpo pueciro trabajaxí algo Oetexminadamonoe sobe la enveñana dela otorguisecum -ra, y Tegias poritionar gue la Focademiar fuede odar in aurai- his cera pracoica ylade tot oficion que penden Cx, illa. are opueses de hiuwo alar oxbenes ce 1.T.1 ye ruego a Oion le gue mial?

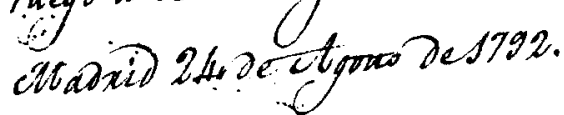

I.

EibL, BOA

$18 \cdot 1$

Fig. 9: VillanueVA, Juan de, Informe sobre los descartes de la muchacheria. Madrid, 24 de agosto de 1792. Firma y rúbrica del arquitecto. A.A.S.F.: Leg.: 18-1/1.

234 
la profesión de arquitecto por contener su pensamiento personal sobre las distintas categorias de los profesionales de la arquitectura.

\subsubsection{La polémica entre Antonio de Varas y los arquitectos}

Pero con ser grave la acusación de Juan de Villanueva a sus compañeros los arquitectos su malestar no debió trascender en la vida académica ni enardecer los ánimos de esos profesores, gracias al hermetismo y la politica prudente del culto Bernardo de Iriarte, el viceprotector. Sin embargo, no ocurriria asi, por desgracia, con otro hecho tan singular como lamentable, que produjo en esta ocasión un profundo malestar entre estos profesionales y sus airadas protestas. Se trata del discurso muy conflictivo, que Antonio de Varas y Portillo, segundo director de Matemáticas, firmó el 9 de octubre de 1792 y leyó públicamente en la junta del dia 28 , produciendo asombro y furor entre todos los académicos y de una forma especial entre los arquitectos, aunque aguantaran su lectura hasta el final, guardando una compostura muy educada y un silencio profundo en ese acto (figs. 10 y 11) ${ }^{31}$.

El discurso de Varas no se ciñó exclusivamente al tema del estudio de las Matemáticas en la Academia, sino que, tal vez por necesidad, abordó el delicado asunto de la formación del arquitecto, quien tenia que recibir a su juicio necesariamente enseñanzas profundas de esa disciplina. Pero, aún basándose en el entonces imprescindible Vitruvio para justificar irracionalmente a base de la critica hiriente y de la burla todos sus argumentos, por lo demás, bastante racionalistas y algunos de ellos no exentos de verdad, no fue capaz de silenciar públicamente, arriesgándose mucho en un medio tan protocolario como el académico, sus resquemores hacia los arquitectos. Tales profesores debian ver el estudio de las Matemáticas, que no corria a su cargo sino de otros docentes especializados, como algo secundario en su formación, teniendo para ellos una prioridad casi total la formación en el dibujo. Este era precisamente el hilo conductor de su discurso y la acusación más grave, además de otras anecdóticas, así como la crítica burlesca, una caricatura, de que en la Academia no se formaban arquitectos, sino académicos ${ }^{32}$.

\footnotetext{
${ }^{31}$ Varas y PORtilla, A. de, Discurso. Madrid, 9 de octubre de 1792. A.A.S.F.: Leg.: 18-20/ 1.

${ }^{32}$ VARAS, Ibidem, fol. 6 reverso. En esta ocasión dice: “Este es el motivo por el que suelen decir algunos que en la Academia de San Fernando no se hacen arquitectos, sino Académicos".
} 


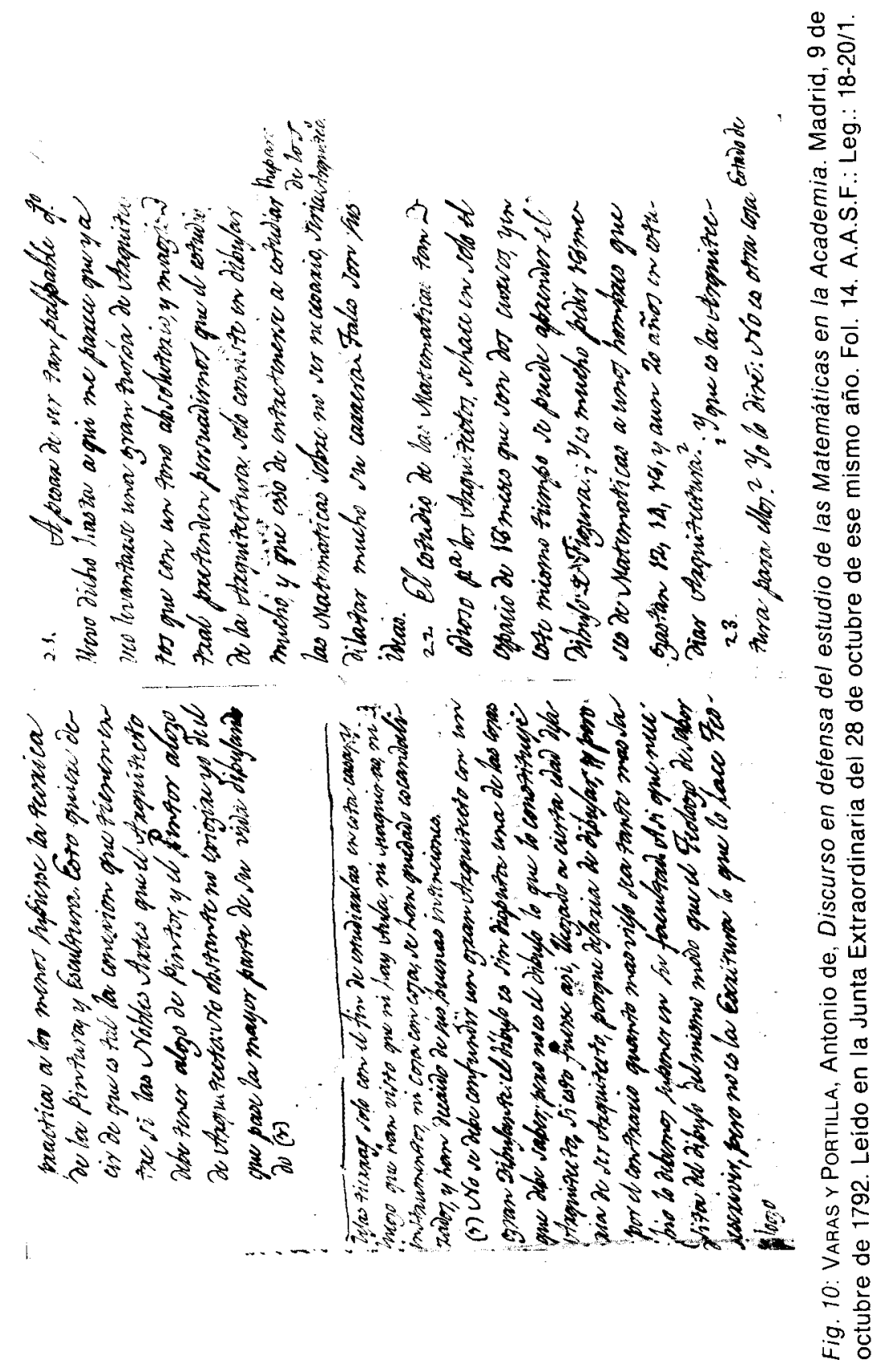




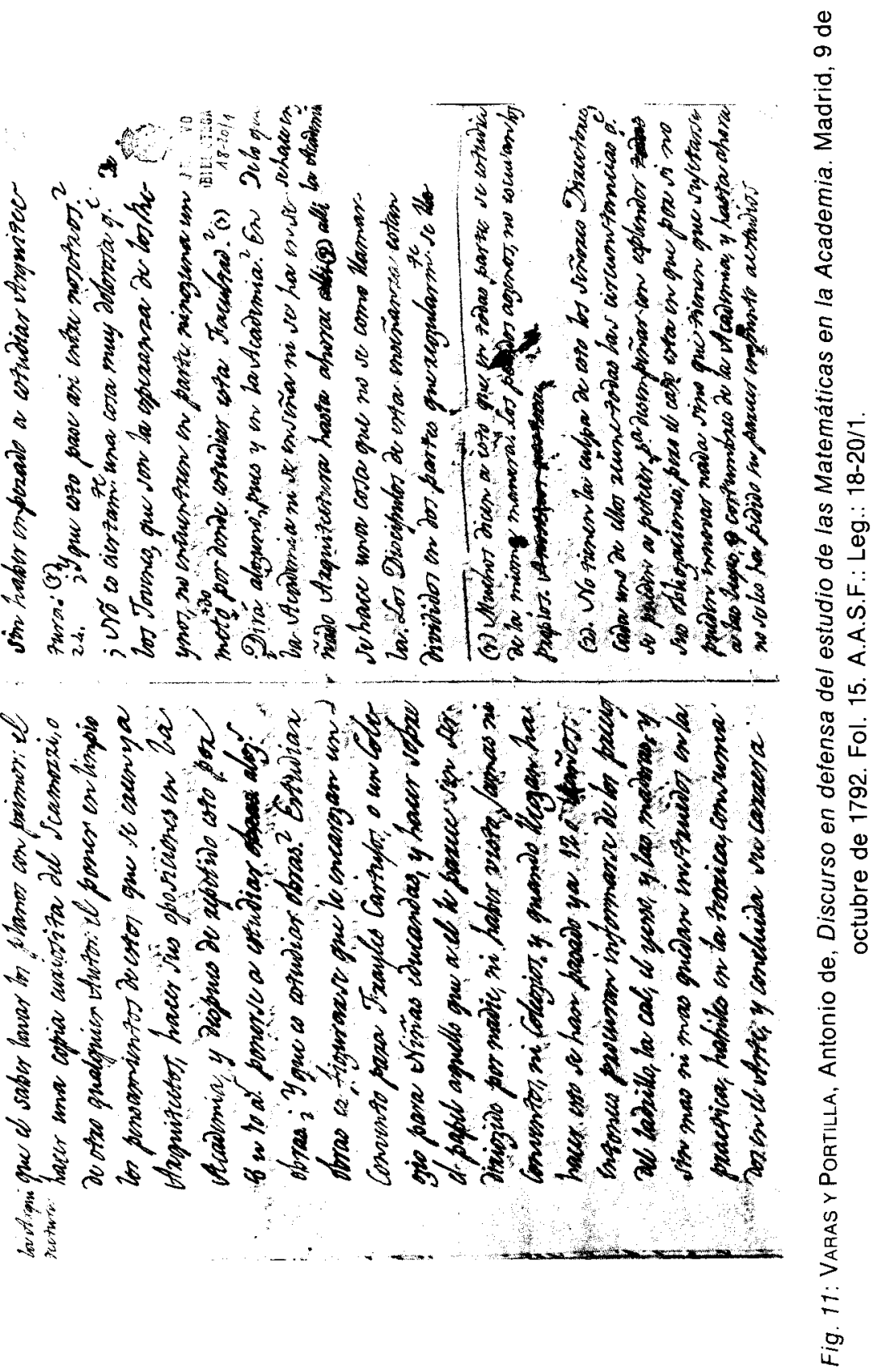


Prescindiendo de los aspectos jocosos por lo demás, bastante abundantes, tentadores y hasta divertidos si no hubieran dado lugar a tantos quebraderos de cabeza para la Academia en este discurso tan polémico, y dejando para más abajo el problema de las relaciones entre el binomio arquitectos matemáticos, hay, o parece existir, un hecho realmente importante ${ }^{33}$. En las postrimerias del siglo de la llustración se cuestiona y se polemiza, más que se debate, sobre tres coordenadas básicas para la formación de todo arquitecto: el tener que elegir entre una arquitectura eminentemente artística, otra científica o una vía intermedia ecléctica y reconciliadora a medio camino entre las dos. Esta era la cuestión realmente esencial en esa controversia, que tanto preocupó y hasta obsesionó por los problemas de orden a los consiliarios, los aristócratas-políticos de este centro de las Bellas Artes, que la gobernaban desde las juntas particulares. Y lógicamente los medios para conseguir cada una de esas opciones eran en algo bastante distintos. La primera exigía un gran desarrollo del dibujo y fuertes nexos con las otras prácticas artísticas; la segunda debia primar las ciencias, las Matemáticas, la Física, la Química..., y la tercera sintetizaria ambas posturas, buscando un justo equilibrio. El eje político de este organismo derivaria en tal sentido, porque en cierta forma obedecia al sistema preexistente.

Las relaciones entre los arquitectos y los matemáticos no debieron ser realmente muy cordiales desde el mismo año, en el que se creó la cátedra de Matemáticas en 1768. En primer lugar porque se les premiaba de alguna forma al distinguir ciertas categorias entre profesores, que quedaban divididos entre directores y tenientes directores de Arquitectura por una parte, y catedráticos de Matemáticas por la otra. También debido a que, después de desecharse por distintos motivos aún no aclarados plenamente desde el punto de vista documental, los intentos de los arquitectos por redactar sus libros de texto y en especial su Arquitectura civil, tan largamente añorada, se habia dado a un matemático la exclusiva de hacerlos y de publicar dicho tratado. Aquellos no debian estar muy conformes con esta determinación, que les descriminaba en gran medida. Se aumentaba, asi, la división entre ellos al diferenciarse entre unos profesores de a pie, que debian "quemarse" en las aulas explicando, y otros más elitistas, que redactaban sus libros, la base de todo sistema didáctico. Benito Bails, el primer catedrático de Matemáticas, vinculado estre-

${ }^{33}$ Varas, Ibidem, fol. 6 anv. La critica hacia los arquitectos bastante jocosa le hizo decir lo siguiente: "Yo, Señores, me lleno de admiración al considerar que la mayor parte de nuestros arquitectos son unos hombres, que solo saben leer, y muchos mal, escribir, gastar la tinta china, y hacer en el papel una distribución de mal y mala manera, y sin más ni más emprenden cosas superiores a sus alc̀ances". 
chamente con Jorge Juan, habia sido el elegido para empresa tan primordial, fracasando antes otros esfuerzos realmente importantes como, por ejemplo, el de José de Hermosilla ${ }^{34}$.

Quizá hubiera una distinta consideración de base entre los matemáti$\cos$ y los arquitectos, que, si bien no se materializaba en el pálpito de la misma Academia de forma elocuente por ser un centro especializado en las Bellas Artes, se realizaba a un nivel social ante el mismo hombre de la calle. A aquellos se les daba de hecho una superioridad científica debido al auténtico universalismo de esta disciplina, que, además, era necesaria, diria mejor imprescindible, para el estudio de otras muchas. Aún siendo fundamental la Arquitectura, sobre todo en un momento de importantes reformas urbanas iniciadas durante el reinado de Carlos III - ahora paralizadas con su descendiente debido a la inflación-, su práctica derivaba de la concurrencia de otras ciencias. Pertenecía conceptualmente a la condición en cierta forma de lujo de las Bellas Artes en un momento, durante el cual se premiaba el pragmatismo. No hay que olvidar aquí, que los arquitectos se dedicaban a las obras mayores, a las realmente representativas, a edificios costosos, abandonándose los otros, las viviendas del pueblo, los cotidianos y por lo tanto las más comunes, por lo general en manos de los gremios y de los maestros de obras por su escasa representatividad en una sociedad fuertemente estamental.

¿Varas defendia, por lo tanto, aún no sabiéndolo expresar a la perfección en su discurso, una arquitectura más moderna, cientifica y hasta tecnológica, totalmente realizable en el futuro, frente a la de los arquitectos de la época anclada en el uso y aún muchas veces en el mismo abuso de exigencias de un conocimiento excesivo del dibujo? ${ }^{35}$. Es muy posible; pero, lo que en realidad deseaba manifestar, era el papel importante que los matemáticos desempeñaban, o deberian hacerlo, en la formación de

\footnotetext{
${ }^{34}$ Sobre el tratado de arquitectura civil de Hermosilla véase el importante estudio de: Rodriguez Ruiz, D., “De la utopia a la Academia: El tratado de arquitectura civil de José de Hermosilla». Fragmentos, núm. 3. Madrid, Ministerio de Cultura, 1985, págs. 57-80.

${ }^{35}$ Varas, A., Discurso. En el fol. 11 rev. y 12 anv. dice: "No se puede confundir un gran Arquitecto con un gran dibujante: el dibujo es sin disputa una de las cosas que debe saber; pero no es el dibujo lo que lo constituye Arquitecto. Si esto fuese así, llegado a cierta edad dejaria de ser Arquitecto, porque dejaria de dibujar; y por el contrario cuando más viejo sea tanto más sabio lo debemos suponer en su facultad. Asi que necesita del dibujo del mismo modo que el Teólogo de saber escribir, pero no es la escritura la que le hace Teólogo. A pesar de ser tan palpable cuanto llevo dicho hasta aqui me parece que ya veo levantarse una gran turba de Arquitectos que con un tono absolutorio y magistral pretenden persuadirnos que el estudio de la Arquitectura solo consiste en dibujar muchio, y que eso de entretenerse a estudiar las Matemáticas sobre no ser necesario, sería dilatar mucho su carrera. Tales son sus ideas".
} 
estos profesionales por considerar totalmente imprescindible el estudio de esa ciencia para la práctica arquitectónica.

Es interesante señalar aqui la reacción corporativa de los profesores de Arquitectura de la Academia a las agresiones sistemáticas contenidas en este discurso (fig. 12). Si unos meses antes Juan de Villanueva se mostró contrario a la Junta de la Comisión de Arquitectura y a sus mismos compañeros, a quienes acusaba de echarse sobre si la realización de los proyectos, ahora se pone al frente de ellos, tomando todas las iniciativas. Hay, asi pues, una reacción gremial, promovida por el deshonor que piensan haber sufrido con las injuriosas criticas muy sarcásticas, salidas de tono, de Antonio de Varas, el segundo director de Matemáticas.

La protesta de los arquitectos se materializó en la representación firmada jerárquicamente el 17 de enero de 1793 por Juan de Villanueva, Pedro Arnal, Manuel Martín Rodríguez, Francisco Sánchez y Manuel Machuca, presentada al todavia novato y muy asustado, palpitante, viceprotector Bernardo de Iriarte ${ }^{36}$. Es de señalar aquí la ausencia del pintor Luis Paret, secretario de la Comisión, quien no hizo causa común con ellos quizás debido a dos motivos: a su mismo empleo, puente administrativo entre estos profesionales y el vértice de la pirámide directiva de tal organismo, y a no ser arquitecto $y$, por lo tanto, a no tener que sentirse ofendido. Tal vez también conociera la crítica que el propio Villanueva le hizo por desempeñar esta función al no pertenecer a esta rama de las Bellas Artes y al desconocerla.

Sin embargo, aunque esa representación fue firmada conjuntamente por todos los profesores arquitectos, numerosos detalles como, por ejemplo, la referencia a su informe reservado y el mismo estilo literario, hacen suponer que fue pensada y escrita sobre todo por el cerebro y la mano del entonces Director General, el autor de los planos del Museo del Prado ${ }^{37}$. Asi parecen certificarlo tambièn las noticias históricas dadas so-

${ }^{36}$ Representación de los arquitectos al discurso de Antonio de Varas. Madrid, 17 de enero de 1793, 30 fols.. A.A.S.F.: 18-20/1. Este documento está firmado por Juan de Villanueva, Pedro Arnal, Manuel Martin Rodríguez, Francisco Sánchez y Manuel Martín Rodriguez. En este mismo legajo se halla una carta de estos arquitectos con la misma fecha dirigida al viceprotector. En ella dicen que devuelven el escrito presentado y leido por Antonio de Varas en la junta de 28 de octubre de 1792, que Iriarte entregó al Director General en la extraordinaria del 18 de noviembre, para que leído y visto con toda atención por los mismos profesores expusiesen su sentir.

${ }^{37}$ Ibidem, fol. 4 rev, y 5 anv. y rev. En este documento se dice lo siguiente: «Si quiere que todos le confesemos con humildad que somos ignorantes, que no alcanzamos todo, que no estudiamos lo que es preciso y debemos saber, lo haremos de buena fe; pero será 


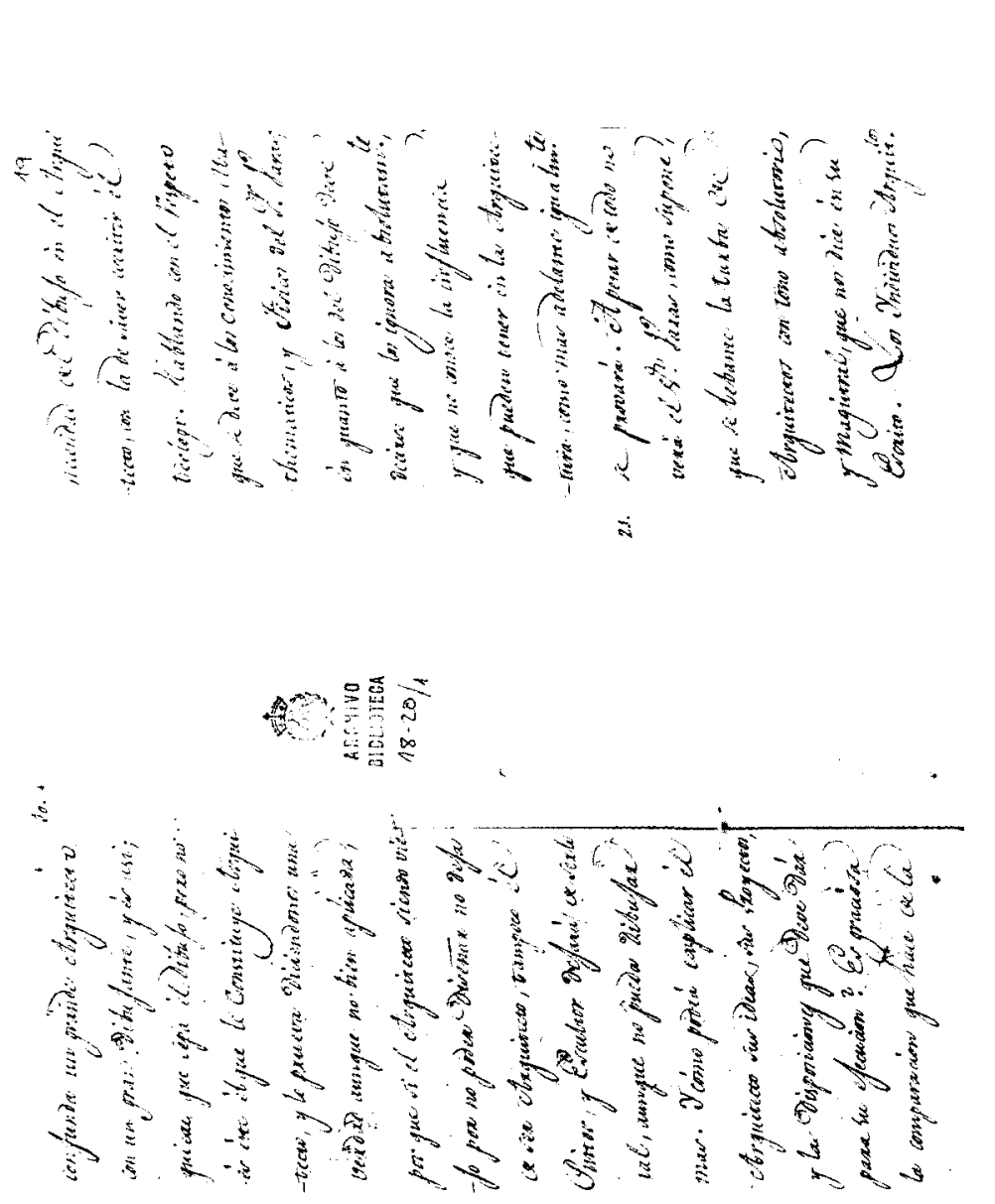

N

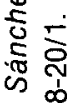

$\stackrel{\infty}{\circ}$

离

近

Ni

$\sum_{0}^{\infty}<$

क्ष

c $\dot{0}$

논

$\Sigma$

$\stackrel{9}{\supset}$

胥

बं

논

운

ำำำ

कृ

เิ

今

$\therefore$

ฮิ

ฐ

๖

$\frac{\pi}{\pi}$

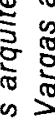

s $>$

8

政

ब

- 8

$x$

핀

过 
bre el pasado de este centro de las Bellas Artes, citas que tan sólo podrian ser bien conocidas por una persona tan vinculada desde siempre con la historia de la Academia como él a través de su propia vida y, asimismo, de la experiencia más bien frustrante de su hermano Diego de Villanueva.

La actitud de los arquitectos ante este discurso fue de protesta firme, y hasta agresiva, por las ofensas recibidas de Antonio de Varas. Antes de enviar esta representación del 17 de enero de 1793 habian decidido no acudir a la junta ordinaria del 4 de noviembre de 1792, lo cual produjo mucho desconcierto y alarma entre los directivos de la Academia, pues en esa misma sesión tenían que haber examinado a un candidato. La inasistencia desesperó a Bernardo de Iriarte, que en sus notas confidenciales dirigidas al secretario Isidoro Bosarte, manifestó todo su desacuerdo, que era mucho, ante la falta de éstos y su intransigente actitud ${ }^{38}$.

Los arquitectos hicieron saber al Viceprotector con cierta dureza su pesar por este irónico discurso de Varas, a quien presentaron, contagiándose precisamente de su mismo tono, como persona conflictiva -el viejo recurso despótico hacia las personas en desacuerdo-, "impetuoso", poseedor de un "celo indiscreto", desconocedor del "lugar donde se hallaba» ${ }^{39}$. Encontraron su escrito de expresiones atrevidas e insultantes, sobre todo en las notas, que consideraban ufuera de los límites y alcances, en que debió contenerse un simple Director segundo de la Cátedra de Matemáticas», a quien también habian considerado como «un individuo extraño de las Tres Artes". He aqui, asi pues, su critica hacia estos profesores, cuya condición dentro de la Academia cuestionaron injustificadamente con esta frase, lo que demuestra el auténtico fondo del proble-

manifestando, que cuanto nos dice lo sabemos, lo conocemos, 10 sabe el viceprotector por su inteligencia propia, y particularmente se lo tiene manifestado reservadamente el Director General, por su precisa obligación, porque los Estatutos le conceden facultad para ello y porque su buen deseo conociendo algun vicio en la enseñanza, alguna escasez, falta de orden y método, tuvo por más acertado manifestarlo sigilosamente para su mejor enmienda, que no públicamente con descompuestas, y altaneras voces, y en escritos que se leen, oyen y exparcen en el público con desdoro de los Cuerpos y de los particulares individuos".

${ }_{38}$ Apuntamientos del Sor. don Isidoro Bosarte, dirigidos al Viceprotector de resultas de lo que éste expuso a la junta particular de la Academia de San Fernando. Madrid, (s. f.: hacia noviembre de 1792. A.A.S.F.: Leg.: 18-20/1. Uno de los apuntamientos más significativos es el siguiente: “ ¿Con qué porque Varas faltó a los Arquitectos, y porque dijo que eran ignorantes en las matemáticas no ha de haber en la Academia enseñanza de ellas? ¿No es esto acreditar que Varas tiene alguna razón? A este modo se seguirá que porque los Arquitectos han faltado a la Academia, chabrá de expulsarlos de su Cuerpo? Nota: La Academia puede serlo de Pintura y Escultura sin necesidad de Arquitectura. Los Pintores y Escultores no necesitan de la Arquitectura. La Arquitectura necesita de ellas".

${ }^{39}$ Respuesta de los arquitectos, ibidem, fol. 1 rev., A.A.S.F:: Leg.: 18-20/1. 
ma, su distinta concepción metodológica, que era la causante del descontento de Varas; pero, también, su mismo dinamismo social, la lucha por conseguir un puesto superior en la escala jerárquica de los profesores dentro de la Academia, reivindicando la importancia y el interés de sus respectivas disciplinas.

Por fortuna la gestión de Bernardo de Iriarte fue fructífera y todo quedó en un mal recuerdo muy desagradable. Antonio de Varas se disculpó en una carta, fechada el 14 de noviembre de 1792, dirigida a este viceprotector. Pedia en ella humildemente que, si tantos problemas había causado su discurso, "si traspasa los límites de la politica, si contiene razonamientos desabridos, justo es y muy justo, que se destruya, que se rompa, que se queme para que no haya más memoria de él», lo cual por suerte no se llegó a hacer ${ }^{40}$. En los mismos términos se expresó en la que dirigió a Isidoro Bosarte ${ }^{41}$, quien el dia 6 de ese mismo mes le habia recriminado duramente por todo ello. Le indicaba en ella, que ese no era ni el medio ni el estilo de escribir para reformar los estudios, "y mucho menos para hablar cara a cara a los mismos que están encargados de su enseñanza» ${ }^{42}$. A lo cual añadia: “Hasta el tono en que Vmd. leyó su discurso los ha irritado: pues parece que cantaba Vmd. el triunfo antes de presentar la batalla".

En este sentido hay que señalar aquí que Bosarte quiso en todo momento desagraviar en su carta el honor ofendido de los arquitectos. Por esta razón añadió lo siguiente en su carta a Antonio de Varas, al expresarle los aspectos, que deberia haber considerado al escribir su discurso, y que aquí reproduzco por su significado reinvindicativo del quehacer de los arquitectos: "/l la honradez tan loable de los Directores, y tenientes, que sufren una fatiga continua de asistencia por una tan corta remuneración como es la que la Academia les da. Y en especial la Arquitectura, para cuya reforma Vmd. escribe, está sirviendo de valde unas Juntas de Comisión en que hay que examinar cuantos planos y pleitos de obras vienen de todas partes por Consejo supremo de S. M. y demás tribunales, y cuerpos distinguidos del Reino. Esta consideración bastaba Sor. D. Antonio para no ensangrentar la pluma contra unos profesores tan honrados de cuya conducta está hasta ahora satisfecha la Academia y el Público de Nuestra Nación. Si hay algun defecto en la enseñanza, podia este ma-

\footnotetext{
${ }^{40}$ VARAS, A., Carta disculpándose del segundo director de matemáticas dirigida al viceprotector. Madrid, 14 de noviembre de 1792. A.A.S.F:: 18-20/1.

${ }^{4}$ Varas, A., Carta dirigida a lsidoro Bosarte, Secretario de la Academia. Madrid, $9 \mathrm{de}$ noviembre de 1792. A.A.S.F.: Leg.: 18-20/1.

${ }^{42}$ Bosarte, I., Carta dirigida a Antonio de Varas. Madrid, 6 de noviembre de 1792. A.A.S.F.: Leg.: 18-20/1.
} 
nifestarse en términos modestos, y no con razonamientos desabridos, palabras insultantes, anécdotas vergonzosas, declamaciones denigrativas, notas picantes, y demás metralla de que está bien cargado el papel» ${ }^{43}$.

Es de señalar aqui, que Isidoro Bosarte en este elogio a los arquitectos no se refirió para nada al Director General, quien muy pocos meses antes parecia comulgar de alguna forma con las ideas de Antonio de Varas 0 , por lo menos con la critica hiriente hacia estos profesionales. Además este secretario debia conocer perfectamente el informe sobre los estudios de la Academia de Juan de Villanueva por estar a su cargo el archivo de los documentos de la Academia.

La polémica quedó aparentemente concluida en la junta particular del 5 de mayo de 1793, que trató monográficamente sobre el escrito de Antonio de Varas, leido en la Junta de examen de estudios, y sobre las quejas y resentimientos de los Directores y Tenientes de Arquitectura ${ }^{44}$. Tal reunión debió celebrarse al insistir Juan de Villanueva en una carta dirigida a Iriarte con fecha del 14 de marzo, interesándose en nombre propio y en el de los profesores de Arquitectura por el curso, que la súplica del 17 de enero habia seguido ${ }^{45}$.

En esa junta particular fueron resumidos con extensión todos los acontecimientos ocurridos durante este incidente, así como las medidas tomadas tanto por el viceprotector como por dicha junta para concluirlo. En ella se analizó ampliamente la "indiferencia o repugnancia», que experimentaba el estudio de las Matemáticas en la Academia. Al mismo tiempo seria delimitado el interés, que una formación en esta disciplina tenía para todas las artes y, de una forma especial, para la Arquitectura. Pero el punto que debió de ocupar más atención y hasta tiempo a esa reunión fue la forma de reinvindicar el "Sonrojado honor y opinión" del cuerpo de arquitectos. En las actas se escribió que la junta particular utiene el concepto más justo de su pericia y acreditada inteligencia y magisterio en la facultad que profesan, como reconoce y estima el más alto grado de celo y esmero". Se decidió satisfacerles adoptando como propio el discurso escrito por el consiliario Pedro de Silva después de la lectura del de Antonio de Varas (figs. 13 y 14). En él se celebraba el talento de los arquitectos, elogiándose, celebrándose y distinguiéndose a los más sobresalientes ${ }^{46}$.

${ }^{43}$ Bosarte, I., Ibidem, fol. 1 rev

44 Acuerdo de la Junta particular del 5 de mayo de 1793. A.A.S.F.: Leg.: 18-20/1.

45 VILlanueva, J., Carta dirigida a Bernardo de Iriarte. Madrid, 14 de marzo de 1793. A.A.S.F.: 18-20/1.

${ }^{46}$ Acuerdo de la junta particular del 5 de Mayo de 1793. A.A.S.F:: 18-20/1 


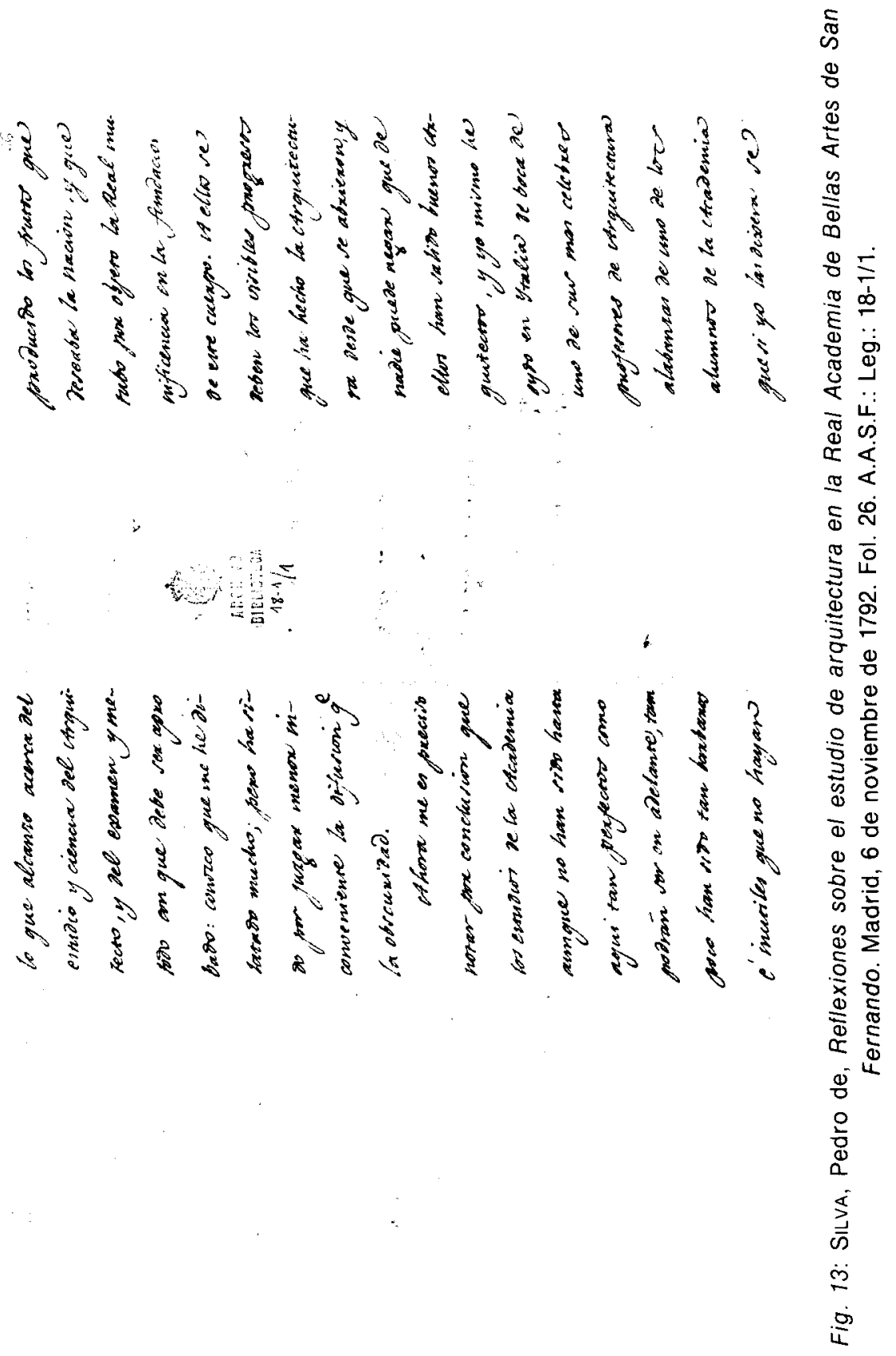




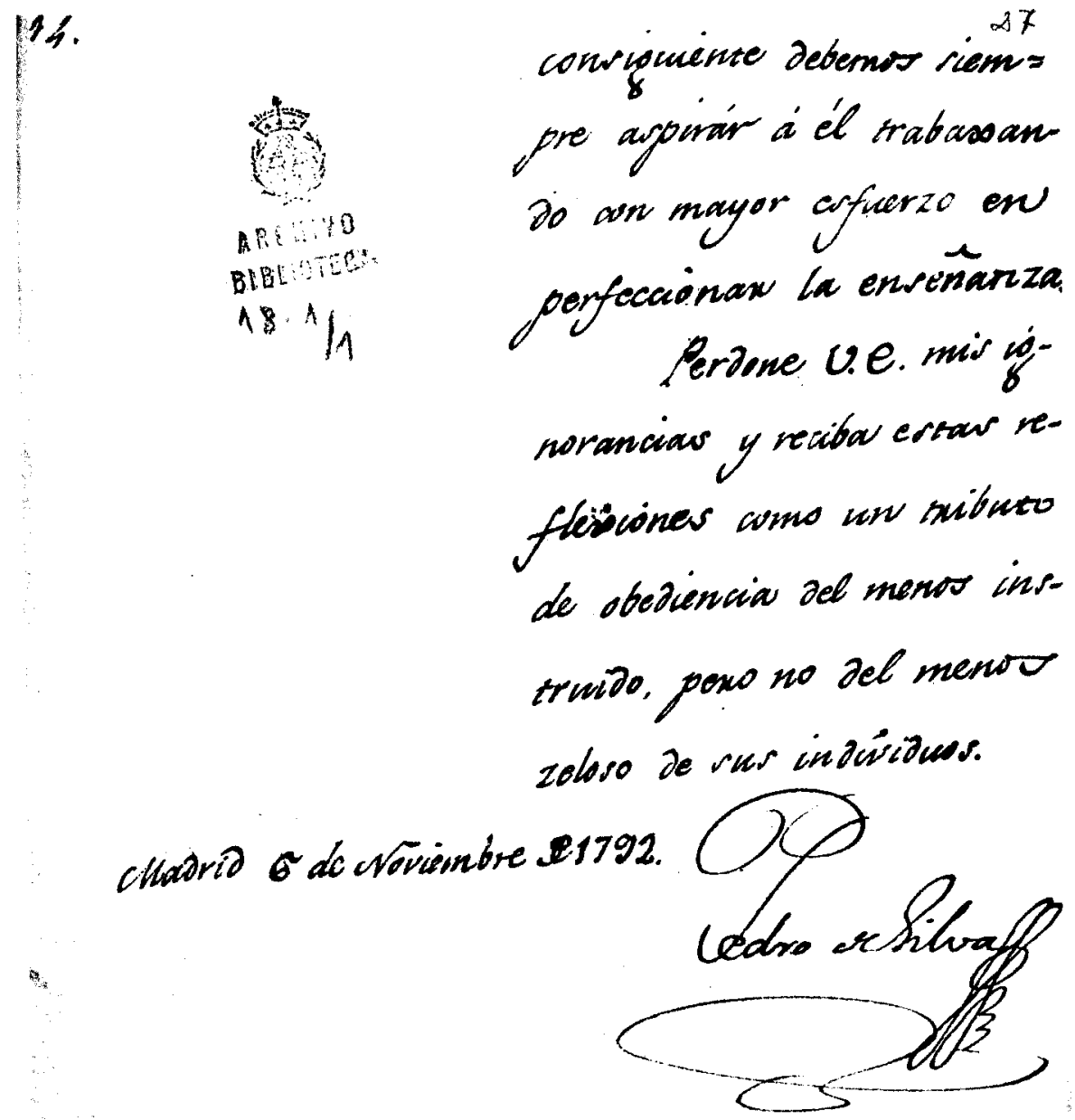

Fig. 14: SiLVA, Pedro de: Reflexiones sobre el estudio de arquitectura en la Real Academia de Bellas Artes de San Fernando. Madrid, 6 de noviembre de 1792. Firma y rúbrica del consiliario. A.A.S.F.: Leg.: 18-1/1. 


\subsubsection{Bernardo de Iriarte y los arquitectos}

Es posible que las ideas de Juan de Villanueva sobre sus compañeros los arquitectos y sus ganas de hacerse con la realización de proyectos a través de la Junta de la Comisión de Arquitectura al rechazar algunos de los remitidos, expuestas con tanta claridad en su informe confidencial sobre los estudios, dirigido al Viceprotector, penetrasen en el subconsciente de Bernardo de Iriarte hasta el punto de hacerlas propias. Pero ahora, bajo la experiencia reciente de la grave polémica suscitada por el discurso de Varas y la intolerancia de estos profesores, incluyó al Director General en el mismo grupo de descontentos, de quienes desconfiaba, centrándose todos sus temores especialmente en Villanueva, que en función de su profesión y de su mismo cargo había encabezado la representación de protesta ${ }^{47}$.

Un motivo protocolario - en cierto modo bastante vanal pero definidor de toda una época demasiada formalista, jerarquizada e intransigenteal cual ya me he referido en otras publicaciones, ocasionó la critica de los profesores de arquitectura por parte de Bernardo de iriarte en el mes de abril de $1793^{48}$. Se trataba de asignar el asiento que Cosme Acuña, Director de Pintura de la Real Academia de Bellas Artes de San Fernando y de sus discipulos pensionados en la de Madrid, ocuparia en las distintas juntas de este organismo madrileño.

Se habia decidido en la reunión ordinaria del 7 de abril, después de varios meses de estudiar el asunto, aplicar la Real Resolución del 21 de enero de 1774 a este problema protocolario ${ }^{49}$. Por esta disposición, que afectaba a los académicos de otras Academias invitados en la de San Fernando, se decidió que Cosme Acuña ocupara un asiento distinguido: el tercero a la izquierda del viceprotector, el que seguia al director más antiguo de este centro, el pintor Antonio González Velázquez. Otra real orden, la del 31 de marzo de 1780, había establecido el protocolo de los directores de la Academia de Valencia en este mismo sentido, resolvien-

${ }^{47}$ IRIARTE, B., Borradores de la carta del viceprotector dirigida al protector Duque de Alcudia. Madrid, abril de 1793. A.A.S.F.: Leg.: 48-1/1.

${ }^{48}$ Este documento lo publiqué en: Garcia Melero, J. E., "Arquitectura y burocracia: el proceso del proyecto en la Comisión de Arquitectura de la Academia (1786-1808)". Espacio, Tiempo y Forma, serie VII, Historia del Arte, t. 4, 1991, págs. 283-348. Véanse págs. 305-311. 233 anv. 
do el caso en concreto de Manuel Monfort, al cual se equiparaba al director de pintura de la Real Academia mejicana ${ }^{50}$.

No obstante, la designación del asiento de Cosme Acuña no satisfizo a varios profesores, que se consideraron agraviados al juzgar que el director de los pensionados tenía muchos menos méritos académicos que ellos para ocupar este puesto preeminente. Francisco Bayeu y Mariano Maella hicieron causa común, amenazaron con despedirse y no volver a la Academia, y se negaron también a asistir a las juntas ordinarias y hasta a las extraordinarias, las más solemnes de este instituto, en las que se requeria a los profesores a fin de emitir sus juicios en el examen de la obras y la adjudicación de los premios trienales. La situación se hacia, así, insostenible en la Academia, pues se temía que otros académicos hicieran causa común con ellos. El viceprotector consideraba totalmente intolerable el comportamiento de ambos y pensaba en la justicia de su represión ${ }^{51}$.

Bernardo de Iriarte intentó por todos los medios disponibles poner fin a tal situación tan alejada del necesario orden tan preciso para el buen funcionamiento del centro. Era partidario de aplicar con buen criterio en todo momento las disposiciones legislativas vigentes, la única forma de ser realmente objetivo en este caso. Pero el malestar parecia crecer en la Academia, motivo por el cual escribió una carta muy expresiva, fechada en abril de 1793 al protector Manuel Godoy, Duque de Alcudia, en la cual le explicaba el problema originado por la designación del asiento de Cosme Acuña según las reales ordenes.

En esta carta, que ya publiqué integramente y en la cual se transparenta a la perfección el carácter temeroso del viceprotector, hay varios

\footnotetext{
${ }^{50}$ Sobre este asunto puede verse en A.A.S.F.: Leg.: 36-3/2. Hay copias en el leg.: 48-1/ 1. Véase en particular el oficio de Isidoro Bosarte dirigido a Pedro Acuña con fecha 8 de abril de 1793, que se halla en dichos legajos. También Antecedente sobre la promiscuidad de asientos en la Academia declarada por S. M. en Real Orden de 3 de agosto de 1793. A.A.S.F.: Leg.: 4-9/1.

${ }^{51}$ IRIARTE, B. de, Notas manuscritas del viceprotector de la Academia sobre la actitud tomada por Bayeu y Maella. (s.f.: julio? de 1793). A.A.S.F.: Leg.: 4-9/1. Bernardo de Iriarte dice en este apunte lo siguiente: "Porque la Academia ha obedecido las Reales Ordenes de S. M. que él resiste obedecer, respecto a la asención para con los Académicos de otros Cuerpos, la trata él desatentamente negándose a asistir a las juntas en términos de no haber concurrido ni aún a las generales para el examen de obras y adjudicación de premios trienales, que es uno de los actos más solemnes del instituto de la Academia, y en que se requiere la asistencia y juicio de los Profesores. Agrégase, y es consiguiente a ésto, la amenaza de despedirse, de no volver a la Academia sólo porque no se le da en ella asiento superior al que está arreglado tenga. Sólo Bayeu y Maella han procedido asi. Los demás profesores, y profesores más antiguos y a quienes más inmediatamente perjudica Acuña no se han ausentado de la Academia, ni han hecho gestión alguna, ni causa común».
} 
aspectos interesantes a considerar, pues describen perfectamente la situación de la Academia. Iriarte se hallaba en la primavera de 1793 ante una serie de acontecimientos muy conflictivos y encadenados desde el otoño de 1792, que parecían certificar que el centro se le iba de las manos poco a poco. Faltaba una autoridad enérgica y efectiva capaz de ponerlos fin. ¿Habian penetrado en la Academia los vioientos aires revolucionarios de la Francia de 1789? Es bastante posible; pero lo interesante es la percepción de un importante cambio de mentalidad en este centro, que no concordaba con la ortodoxa y precisa armonia del clasicismo, la tan conocida moderación griega.

La carta de Bernardo de Iriarte, no exenta de cierta carga poética, denunciaba al protector este ambiente. Le prevenia, apercibido como estaba quizás por sus propios espias, que los profesores intentaban entregar al Rey un escrito por medio o de su arquitecto Juan de Villanueva o de su pintor Francisco Bayeu. Se rompian asi las estructuras jerárquicas tradicionales de representación de la Academia, cuyos miembros tan sólo podian comunicarse con el monarca a través del protector y tras de pasar por la censura previa del viceprotector. Ahora se utilizaba a los artistas reales, vinculados también con este organismo, para llegar ante la presencia directa del mismo Carlos IV sin necesidad de que mediara el cuerpo directivo de los consiliarios ni las juntas oficiales también jerarquizadas, especialmente la particular, la realmente decisiva.

El orgullo de los profesores era el tema que parecia más preocupar a Iriarte, soberbia que motivaba graves y continuos desórdenes en su conducta académica. Pero halló, además, ocasión para manifestar a Godoy su temor hacia los arquitectos, que estaban adquiriendo cada vez un poder mayor al tener capacidad legal para controlar cuantas obras públicas se construian en el Reino a través de la Comisión de Arquitectura y también de ganar, asi, mucho más que los otros artistas. De este modo al viceprotector parecia irsele de las manos su propia función y también perder su poder de una forma realmente efectiva.

En efecto, Francisco Bayeu, primer pintor de Cámara del rey, presentó a Carlos IV una súplica fechada el 15 de mayo de 1793. No habia sido el arquitecto Juan de Villanueva el autor de este escrito, tal y como Iriarte pensaba, sino Bayeu, de quien también sospechaba y que se habia manifestado especialmente beligerante en este asunto al sentirse de una forma personal afectado por la determinación de la Academia. En la representación pedia al monarca, que se le otorgaran los honores de director general para poder sentarse en las juntas delante de los demás profesores directores, pues su honor se sentía rebajado al haberse concedido 
a Cosme Acuña un asiento prioritario por el simple hecho de ser el director de los discípulos mejicanos pensionados en Madrid ${ }^{52}$.

Carlos IV remitió esta súplica a Bernardo de Iriarte a través del protector Duque de Alcudia, para que la Academia la estudiara e informase, lo que considerara oportuno. Sin embargo, el viceprotector la devolvió seguidamente con la indicación lacónica, pero exacta, de que este Real Cuerpo habia procedido en todo con arreglo a las resoluciones reales, y, añadió, que la queja de Francisco Bayeu era infundada. Poco después el rey la volvió a remitir de nuevo a Iriarte. Carlos IV, al parecer, pensaba que era injusto, que a los individuos de otras Academias establecidos o que se estableciesen en Madrid se les debieran hacer los mismos honores que a los transeúntes.

El asunto fue estudiado una vez más por la Academia en las juntas particulares consecutivas del 7 y 9 de julio de 1793. Se examinó el memorial de Bayeu, los antecedentes de Cosme Acuña, los del grabador valenciano Monfort y todas las Reales Ordenes y estatutos, que se referian a los honores académicos y de asientos en las juntas. Se acordó denegar a Bayeu su extraña pretensión basándose en la falta de precedentes sobre el particular y, además, porque, en el caso de concedersele los honores de director general por este motivo, la resolución motivaria unas aspiraciones similares por parte de otros profesores igualmente afectados por el mismo asunto.

La solución al problema fue salomónica y hasta revolucionaria en este momento, aunque siempre dentro de la configuración estamental de la Academia. Después de que los consiliarios discutieran largamente el asunto decidieron por pluralidad de votos, pues se dividieron en dictámenes, que los asientos de señores y profesores fueran indiferentes y promiscuos en sus respectivas bandas. Cada uno ocuparia el que hallara desocupado al tiempo de sentarse. Quedaban tan solo inalterables los asientos del viceprotector, del secretario y del director general, los tres cargos más representativos y politicos de la Academia.

Iriarte opinaba que tal decisión de la junta terminaria con las disputas; pero que no agradaria a los profesores. Era muy difícil contentarlos a todos en este momento y en los sucesivos, pues las providencias, que unos aprobaran, serian rechazadas por los otros, y que lo que entonces agradaba, desagradaría dentro de poco tiempo. Los consiliarios estaban

\footnotetext{
${ }^{52}$ Antecedente sobre la promiscuidad de asientos en la Academia declarada por S. M. en Real Orden de 3 de Agosto de 1793. A.A.S.F.: Leg.: 4-9/1.
} 
convencidos, de que difícilmente se podría contentar a todos los profesores ni evitar consecuencias sensibles.

Tal resolución de la junta particular fue remitida oficialmente a Carlos IV el 20 de julio. El rey, siempre a través del protector duque de Alcudia, aceptó esta disposición, y la comunicó a los consiliarios y académicos de honor por la Real Orden del 3 de agosto de 1793. Se derogaron el artículo o artículos de los Estatutos de la Academia, que se ocupaban de este asunto, asi como todas las disposiciones posteriores ${ }^{53}$.

Pero, además de destacar la situación de malestar que los problemas protocolarios, jocoserios, provocaron en la Academia en este momento realmente complejo, interesa aqui acentuar el juicio que la actitud belicosa de los arquitectos merecía al viceprotector, la cabeza política de este centro de las Bellas Artes. Parece bastante claro que su poder siempre en aumento preocupaba seriamente al estamento directivo de este instituto. $Y$ posiblemente Iriarte se habia dejado contagiar por el informe sobre los estudios del propio Juan de Villanueva, quien, antes de hacer causa común con ellos, le habia llamado la atención sobre el particular. Quizás los profesores de las otras artes también participaran de tal inquietud, acrecentada con su polémica con el matemático Antonio de Varas sobre los estudios de la Arquitectura, de la que todos eran testigos.

No parece osado insinuar aqui que en la historia de estos conflictos ocurridos entre 1792 y 1793 se puede hallar ya uno de los motivos, aunque todavia sin duda algo remotos en el tiempo, causantes de la separación de los arquitectos de la enseñanza en la Academia y la creación ya el 25 de septiembre de 1844 de la Escuela de Arquitectura de Madrid. Se iban diferenciando, así, entre los arquitectos como profesionales más técnicos, cuya práctica incidia directamente en la sociedad a través de la vivienda y de la ciudad misma, y los otros artistas quizás más creativos, pero también tal vez menos técnicos. La formación de los arquitectos era mucho más compleja, pues exigia numerosos conocimientos de otras disciplinas como, por ejemplo, las matemáticas y la física. También contribuyó en esta diferenciación la creación en 1786 de la junta de la Comisión de Arquitectura, organismo que con el tiempo adquirió una gran autonomia y, por lo tanto, poder con relación a la Academia.

${ }^{53}$ En el legajo 4-9/1 hay una copia de mano de Juan Pascual Colomer, fechada en Madrid el 18 de diciembre de 1817, de la Real Orden de 3 de agosto de 1793 declarando la promiscuidad de asientos en las juntas. 


\section{ORTODOXIAS Y HETERODOXIAS ACADEMICISTAS}

Todos estos acontecimientos proporcionan la idea de que las heterodoxias académicas, tan temidas como las ideas revolucionarias del 89 , estaban penetrando en la Academia a un nivel general al aparecer múltiples conflictos ambivalentes, de comportamiento académico y hasta a un nivel teórico, que parecian entremezclarse y hasta confundirse. Artistas tan destacados como Francisco de Goya (fig. 15) y Juan de Villanueva, sin duda los más importantes de la época en sus respectivos géneros, cuestionaban de algún modo en sus escritos, dejando asi un claro testimonio de ello, la oportunidad de la misma Academia y el clasicismo como única verdad artística, y ponían en tela de juicio los postulados mismos de Mengs, que habian dirigido a este organismo durante tantos años.

Si Juan de Villanueva ya habia realizado entonces, en 1793, los proyectos de sus principales edificios, Goya experimentaria desde ese mismo momento un cambio bien significativo en su estilo, que, por lo demás, casi nunca había estado condicionado por la ortodoxia clasicista, sino por el interés que tenia por la Academia como centro y como una forma de progresar y de realizarse artisticamente (fig. 16). El arquitecto introdujo desde sus casitas de El Escorial en su práctica arquitectónica el elemento palladiano, un manierismo, como un modelo prioritario, que en sus obras fusionó con la herencia de Herrera, haciendo una constante personal de esta simbiosis. Hay que recordar aquí la importancia que Palladio tuvo en la aparición y el desarrollo del romanticismo histórico, siempre basado en la recreación de la Historia con toda su multiplidad. Villanueva plataformó en España esta tendencia clasicista hacia su culmen y también hacia su misma crisis con la diversificación de los modelos y la penetración de la óptica del último renacimiento, del período más amanerado y quizás creativo. $Y$, así, al poco tiempo de ser, o tal vez de aspirar a existir, lo confundió.

Resulta bien significativo que Goya, escasos dias más tarde de escribir su informe y después de atravesar por una fase critica propiciada por la persecución de sus amigos los afrancesados, sufriera su misteriosa enfermedad. $Y$ bajo estas dos coordenadas vitales aparecieron los fantasmas en sus cuadros, que tanto le identifican con una actitud y un estilo románticos con la ruptura de la forma y el desbordamiento del colorido, aún siendo el negro. Todos estos hechos certifican una mutación romántica en el sentido baudeleriano de este término, en el modo de ser y de sentir, y, asimismo, en los temas, el color y las formas empleadas. Cambios bien distantes del rígido, uniforme, monótono y hasta algo gris, $y$ convencional clasicisimo de sus compañeros en la Academia. 


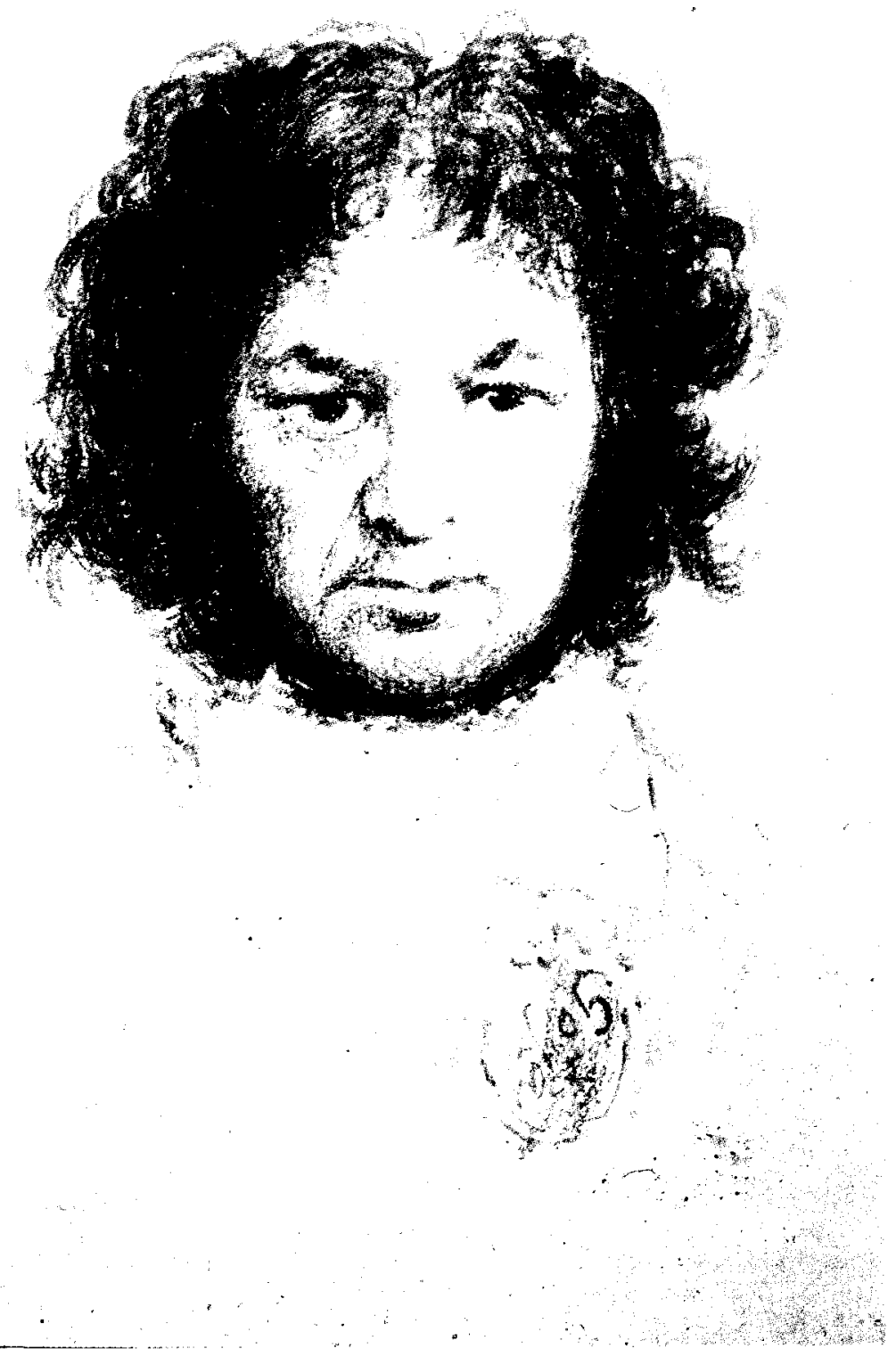

Fig. 15: Goya y LuCIENTES, Francisco de, Autorretrato. Hacia 1800. Pincel con aguada gris. Nueva York, Metropolitan Museum of Art. 


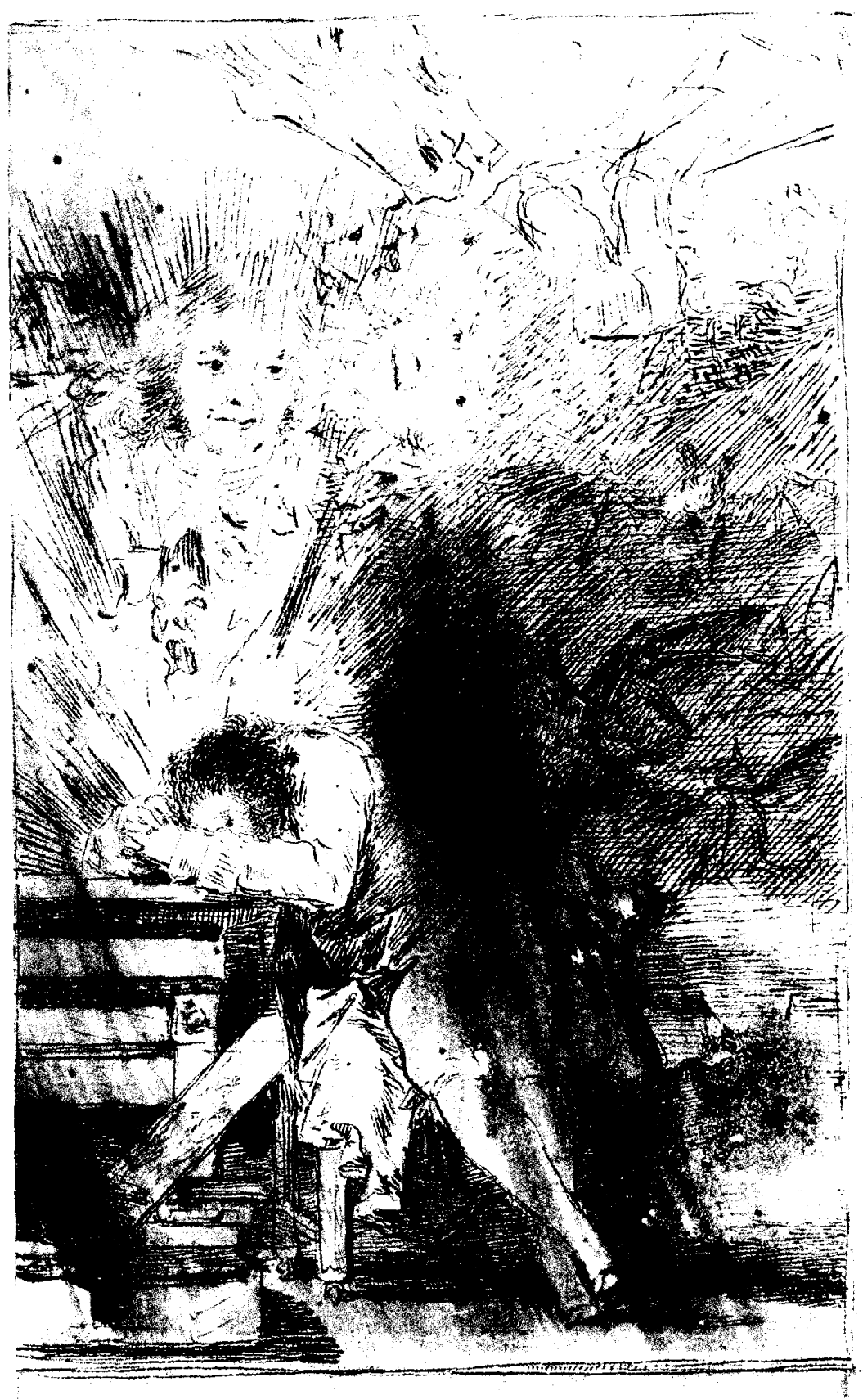

Fig. 16: Goya y Lucientes, Francisco de, Frontispicio de los Sueños. Pluma con tinta negra y sepia sobre ligero esbozo de carbón. 1797. Madrid, Museo del Prado. 
Las actitudes tomadas por Goya y Villanueva ante la vida en la Academia - que son también el simple reflejo de sus propias vivencias, su existencia misma - fueron en algo muy similares pero también bastante distintas entre si. La posición claramente crítica, la ruptura, o el intento, con los encasillamientos rígidos, les une; pero política y estética les separan, pues, si el arquitecto pensó en este organismo desde una perspectiva organizativa y pedagógica, el pintor plasmó en su informe de extensión menor y más concreta su pensamiento critico-poético. En Villanueva pesaba más la tradición de este centro docente de las Bellas Artes largamente vivido por él a través de su propia experiencia y la de su hermano Diego que en Goya, mucho más indiferente hacia su pasado.

El pintor fue más lírico en su corto, pero muy expresivo informe, en el que no se fijó en los pormenores de la Academia, sino en sus líneas más etéreas y generales; por el contrario, el arquitecto resulta más épico en su escrito extenso y minucioso, perfectamente estructurado, concebido como si se tratara de un edificio. El texto del uno parece más efimero y volatil que el del otro tal vez más inamovible. Villanueva dejó traslucir su universo, todo su carácter, de sombras y de luces. Goya es más claro en su estricta actitud romántica, en su apasionamiento. El humanismo de aquél parece contrastar con la vinculación con la divinidad de éste último, quien un tanto místicamente se complace en relacionar la creación artística con Dios, restableciendo un binomio entre el Arte y la Divinidad pasando siempre por la Naturaleza, y prescindiendo de la Antigüedad clásica, a la que critica. Goya desea romper, y rompió, con el pasado, mientras que Villanueva no logra desasirse plenamente de toda la tradición clásica, fluctuándo y girando siempre, muchas veces recreándola. Si en el uno pesa, al conjugarse en su arquitectura y su escrito, la carga histórica con la que juega ya casi románticamente combinándola recreativamente, en el otro la Historia parece desintegrarse en mil pedazos, historiando el presente, que transmuta y proyecta hacia el futuro.

Es, asi pues, mucho más clara la actitud romántica de Goya que la de Villanueva, quizás menos evolucionado. Pero ambos muestran su disconformidad con el mundo académico y con su estricto clasicismo. El pintor habla de libertad, de cese de los despotismos, de dar fin a la opresión, porque las Bellas Artes "no deben ser arrastradas del poder». Y Mengs, uno de los ejemplos entonces más significativos de la normativa académica, de las cadenas del clasicismo dieciochesco, es debatido, criticado y puesto en tela de juicio por el mismo Goya con el empleo de un lenguaje de libertad.

Juan de Villanueva cuestionó al ser nombrado director general de la Academia la existencia misma de este centro docente, criticando con du- 
reza y pesimismo su situación y la de las Bellas Artes en la España de la época. Si en su informe educativo se halló a medio camino entre la tradición y la novedad, en su posterior vida académica, ya en 1793, se manifestaria como un politico defensor del honor y de los derechos de sus compañeros arquitectos, a quienes antes habia criticado. En este sentido se mostró como un conservador, que defendia el "status" social de un grupo de profesores especializados, del cual formaba parte, frente a las criticas de un profesional de las Matemáticas.

Los ortodoxos de la Academia en apariencia no cuestionaron sus objetivos, ni las teorias en las que se basaban los postulados clasicistas. Los asumieron todos ellos como primeros principios indemostrables. Se desarrollaron en este organismo desempeñando una función múltiple a la vez artística, pedagógica y hasta muchas veces burocrática, que en ocasiones restó efectividad a su capacidad creativa. Los arquitectos, que buscaban en su actividad la perfecta conjunción clásica entre teoria y praxis, desempeñaron una función importante desde la Comisión de Arquitectura de la Academia al depurar a partir de los modelos clásicos los proyectos de las principales obras públicas, que se diseñaron en España entre 1786 y 1808.

Los informes sobre el estudio de la arquitectura escritos por Manuel Martin Rodríguez el 30 de septiembre de 1792 y por Francisco Sánchez el 14 de octubre se hallan en esta misma linea ortodoxa; pero sin aportar ninguno de ellos un gran saber teórico de los textos del clasicismo. El primero aludió a Grecia y Roma, como modelos arquitectónicos de referencia obligada, demostrando al señalar aquellas partes de edificios, que se debian vaciar para traer a la Academia, un profundo conocimiento de las ruinas. Tampoco podría faltar, obviamente, en su escrito la referencia a Vitruvio, debiéndose elegir según su parecer a uno de sus comentaristas para evitar la confusión de los discípulos (figs. 17 y 18) ${ }^{54}$.

En este mismo sentido se manifestó Francisco Sánchez, quien demuestra en su informe una gran obsesión por el diseño de las distintas tipologias arquitectónicas. Con un carácter muy funcional, eminentemente práctico, eligió los textos del clasicismo en relación siempre con las diferentes clases de edificios, prefiriendo a Vitruvio en los templos y en las casas de campo a Serlio, Palladio y Escamozi. Las tipologias recomendadas para su estudio se hallan en. relación con los distintos tipos de

54 Martin Rodriguez, M., Propuestas para el arreglo de estudios de la Real Academia de San Fernando. Madrid, 30 de septiembre de 1792. 2 fols.. A.A.S.F.: Leg.: 18-1/1. 


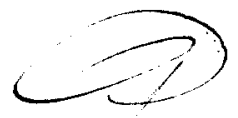

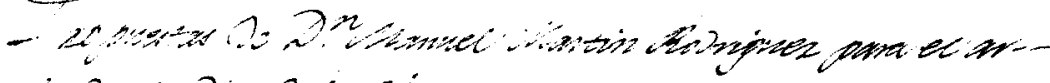

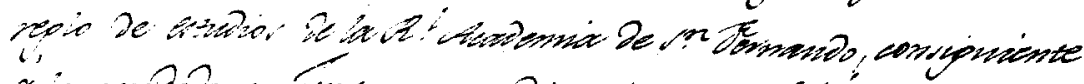

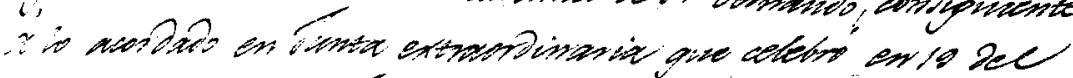

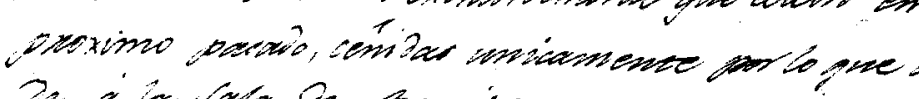

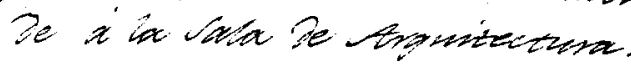
2
2

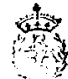
IIITIVO BIBLIOTECA 18. $1 / 9$

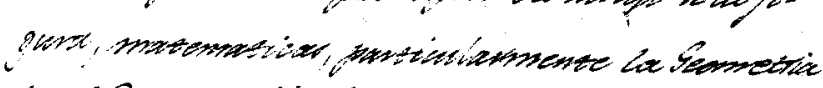

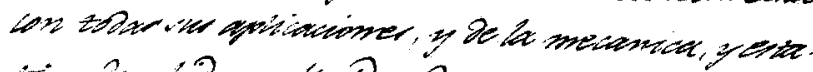

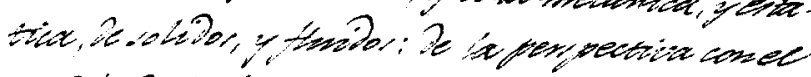

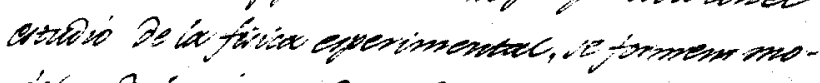

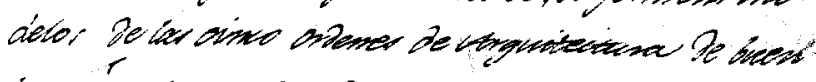

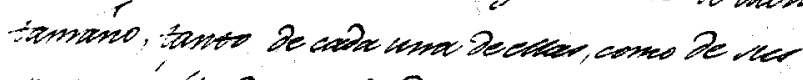

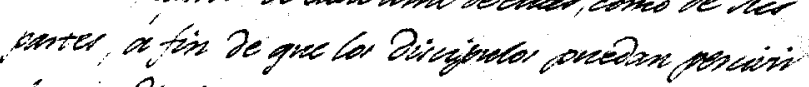

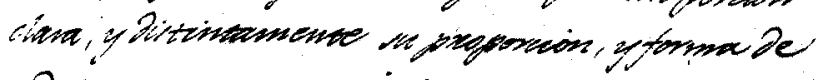

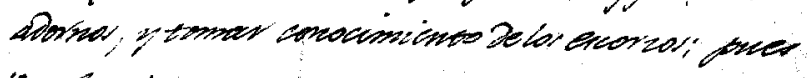

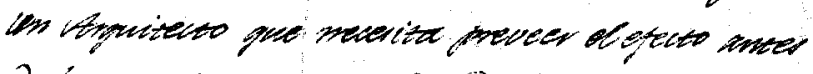

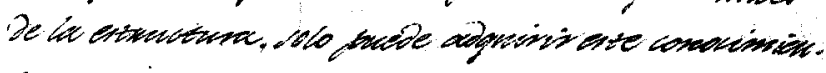

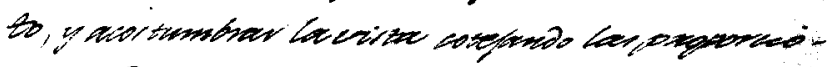

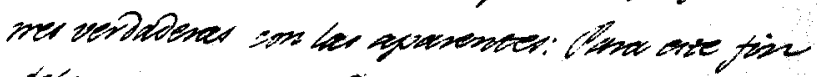

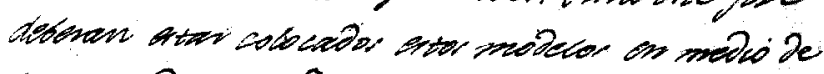

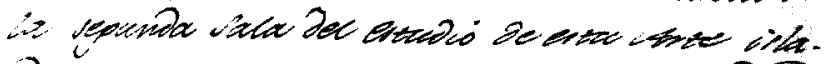

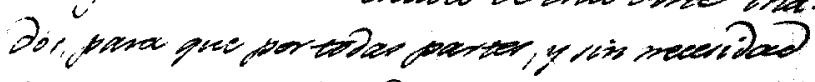

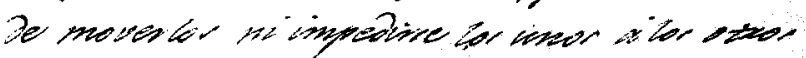

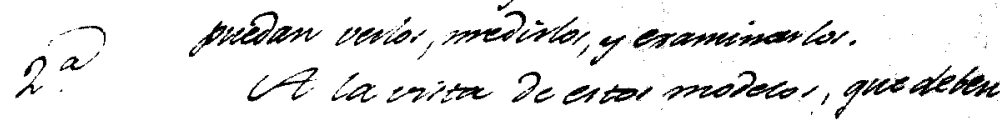

Fig. 17: Martin Rodriguez, Manuel, Propuestas para el arreglo de los estudios de la Real Academia de Bellas Artes de San Fernando. Madrid, 30 de septiembre de 1792. Fol. 1 anv. A.A.S.F.: 18-1/1. 


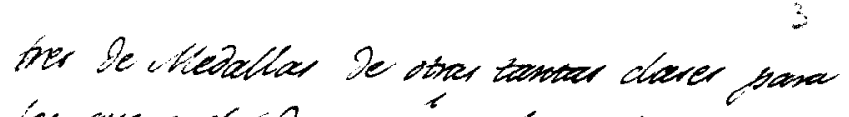

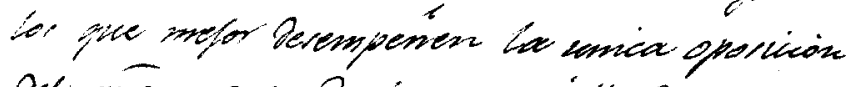

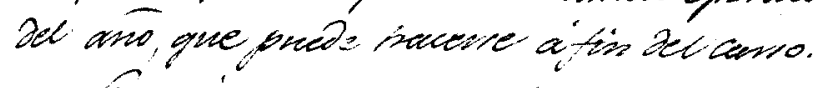
tito ef guant re mo árece pxoponer;

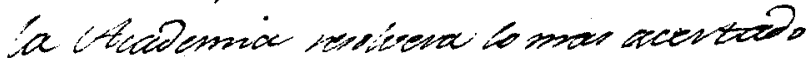
torives $30 \mathrm{de} 1702$
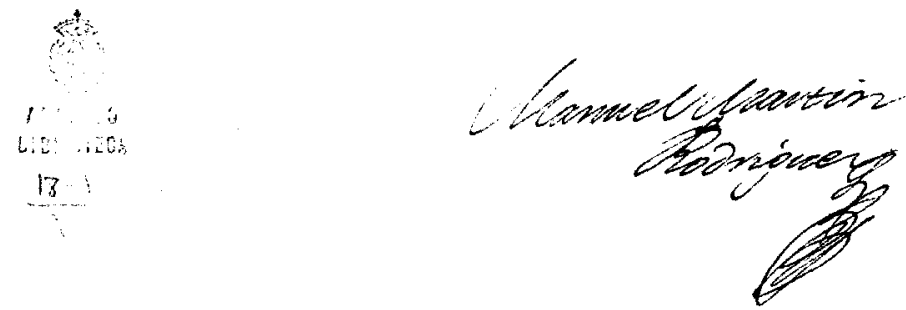

Fig. 18: Martin Rodriguez, Manuel, Propuesta para el arreglo de los estudios de la Real Academia de Bellas Artes de San Fernando. Madrid, 30 de septiembre de 1792. Firma y rúbrica del arquitecto. A.A.S.F.: Leg.: 18-1/1. 
proyectos, que llegaban a la Junta de la Comisión de Arquitectura (fig. 19) ${ }^{55}$.

Pero muchas veces, lo cual es bien significativo, en las mismas ortodoxias se hallan paradójicamente las mutaciones teóricas al tratarse de encontrar las bases firmes y justificativas de todo un sistema de representación formal y social en la tempestad de la Historia. El clasicismo, como lo seria el romanticismo, es, además de un lenguaje artístico, un modo de expresión estético, también un comportamiento en sociedad. Forma y norma, estética y ética, se conjugan en estas actuaciones en la teoria y en la práctica del ocaso del siglo de la llustración siempre bajo la doble óptica o de la estricta uniformidad y universalismo o de la libertad, la ruptura y el individualismo. Dos posturas la mayoria de las veces tan contrapuestas que en el crepúsculo del siglo de la razón -tal y como casi siempre suele suceder en los momentos de un racionalismo extremo, que raya con la caricatura-, en los ambiguos años de tránsito entre siglos, coinciden, aunque a veces algo tímidamente, y contrastan entre sí, como si vaticinaran el inicio de una época de la "sin razón".

Los literatos de la Academia - de una forma paralela con los artistas y en especial con los arquitectos y posiblemente en diálogo teórico-los Jovellanos, Ponz, Bosarte, Llaguno, Ceán..., al tratar de justificar históricamente la inamovible universalidad del clasicismo como el verdadero estilo, percibieron la existencia de los momentos heterodoxos, de los que imperceptiblemente se contagiaron de alguna manera. Es en concreto la búsqueda en el pasado de la grandeza de ese clasicismo el motor que propició su misma crisis y el origen de los historicismos de diverso sino, que caracterizaron el ir y el venir, el eterno devenir, del arte del siglo xIx, la cíclica ola de la Historia. Y en este entorno de 1792 se produjo el inicio de la crisis de identidad del clasicismo, si, paradójicamente, alguna vez llegó a existir y no fue una simple, pero ya vieja, aspiración, un espejismo soñado y una utopia bien bella.

Quizá sea posible el afirmar aqui que la arquitectura española de la llustración, así como toda la teoría y práctica artística academicista, fue el ensayo rápido, a veces centelleante, de cuantos acontecimientos formales, comportamientos estéticos y hasta éticos, ocurririan después durante todo el siglo xix. Ensayos casi de probeta, que se valieron de la revisión de la historia del arte como medio. Se establecieron entonces las bases ideológicas fundamentales para realizar un auténtico estado de la

${ }_{55}$ SANCHEZ, Francisco, Su parecer para el mejor reglamento del estudio de Arquitectura. 3 fols.. A.A.S.F:: Leg.: 18-1/1. 


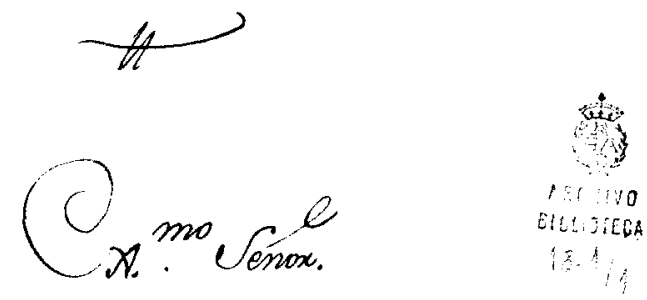

(C) conregiencia w lo que H.C. ve rixse man daxme robxe que esponoa m paxecex paxa $\mathrm{el}$

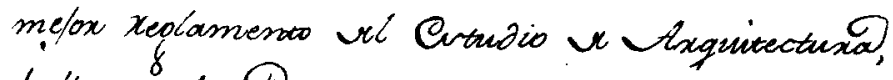
hallo que los Ohxectoxer que ha habido havia ec pxereme, derde elertablecimiento vla B. Stade-

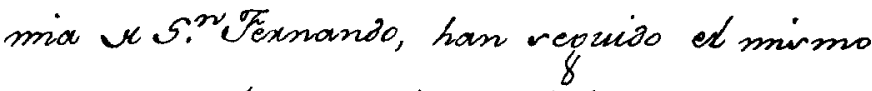
método que hoy re rioue; á lor querdebe élade Lantamiento que re nota en el dia; pexo obedecien

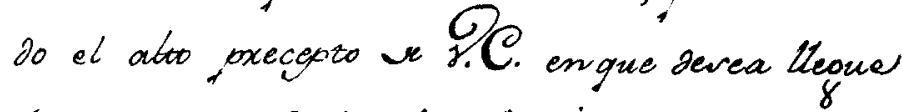
a mayox pexfecion la Axgritectuxa?, cno obstante Señox, gue me convizexs el menos äbit, é incopoin paxa podex derempeñax este encaxpo, acoxbandome we aguelloy gxander Dixectoxer gue ha habido, I hay al pxevente, mamifierto mi paxecex, anngue con xubox; $y$ es, gue despwer $x$ habex ext diato la Feometxia, aumentando a esta las Vecciones comicar, pox ru estendida, y lame-

Fig. 19: SÁNCHEZ, Francisco, Parecer sobre el estudio de la Arquitectura en la Academia. Madrid, 14 de octubre de 1792. Fol. 1 anv. A.A.S.F.: Leg.: 18-1/1. 
cuestión del pasado para ser proyectado hacia el futuro. Asi, es imposible acercarse al romanticismo histórico sin haber analizado antes esta época con vocación clasicista, pero que se dejó enredar por la historia de diverso sino. 
